\title{
Understanding the Adsorption of Quinoxaline Derivatives as Corrosion Inhibitors for Mild Steel in Acidic Medium: Experimental, Theoretical and Molecular Dynamic Simulation Studies
}

\author{
Lgaz $\mathrm{H}^{1,2}$, Salghi $\mathbf{R}^{2}$, Jodeh $\mathrm{S}^{3}$, Ramli $\mathbf{Y}^{4}$, Larouj $\mathbf{M}^{1}$, Toumiat $\mathrm{K}^{5}$, Quraishi MA ${ }^{6 *}$, Oudda $\mathrm{H}^{1}$ and Jodeh $\mathbf{W}^{7}$ \\ ${ }^{1}$ Faculty of Science, University Ibn Tofail, Morocco \\ ${ }^{2}$ Laboratory of Applied Chemistry and Environment, Ibn Zohr University, Morocco \\ ${ }^{3}$ Department of Chemistry, An-Najah National University, Nablus, State of Palestine \\ ${ }^{4}$ Medical and Pharmaceutical College, University Mohammed V, Morocco \\ ${ }^{5}$ Department of Materials Sciences, Laghouat University, Algeria \\ ${ }^{6}$ Department of Chemistry, Indian Institute of Technology, Uttar Pradesh, India \\ ${ }^{7}$ Department of Human Medicine, An-Najah National University, Palestine
}

\begin{abstract}
The anti-corrosive properties of (E)-3-styrylquinoxalin-2(1H)-one (STQ), (E)-1-benzyl-3-(4-methoxystyryl) quinoxalin-2(1H)-one $(B M Q)$ and $(E)-3-(2-(f u r a n-2-y l)$ vinyl) quinoxalin-2(1H)-one $(F V Q)$ were analyzed by different techniques such as: potentiodynamic polarization, electrochemical impedance spectroscopy (EIS), weight loss (WL) and molecular modeling by DFT method and Monte Carlo simulation studies. All quinoxaline derivatives showed appreciable inhibition efficiency. Among the quinoxaline derivatives studied, BMQ exhibited the best inhibition efficiency. The results from the experimental and theoretical investigations show that the order of inhibition efficiency by the quinoxaline derivatives follow the order BMQ $>$ FVQ $>$ STQ. The experimental results suggest that the three tested inhibitors function as mixed-type compounds and the inhibition efficiency increases with the increase in inhibitor concentration and decreased with temperature. Adsorption of the three compounds on mild steel (MS) surface obeys Langmuir's isotherm model. The theoretical study by DFT method, Monte Carlo simulation and radial distribution function (RDF) provided strong evidence that the inhibition efficiency of quinoxaline derivatives is due to their ability to adsorb strongly at the MS surfaces, which is supportive of the obtained experimental results.
\end{abstract}

Keywords: Monte carlo; Quinoxaline; Mild steel; Corrosion inhibition; Fukui functions; DFT

\section{Introduction}

Mild steel is an iron-containing alloy, considered as one of important constructional materials extensively used in different applications. Generally, acid solution (especially hydrochloric acid) plays a significant role in many fields of industry such as pickling, descaling and oil well acidification, its price is generally low and more consistent $[1,2]$. In the few last decades the use of chemical compounds as corrosion inhibitors is considered as one of the efficient and practical methods to protect the metals surfaces against aggressive mediums such as acidic solutions [3-5]. The effectiveness of these molecules is mainly from their ability to adhere to metal surfaces [6]. The use of synthetic inhibitors also appears to be economically viable and promising because of their simplicity in application, and they're relatively cheaper. Meanwhile, the adsorption of these inhibitors produces a protective insoluble film on the MS surface, which reduces contact with the corrosive mediums and consequently the degree of metal attack [79]. The presence of $\mathrm{N}, \mathrm{O}, \mathrm{S}$ atoms and conjugates aromatic nucleus are responsible for their essential characteristics [10]. The quinoxaline is one of the important heterocyclic compounds; they have applications in many fields such as electroluminescent materials [11,12] and in the pharmacological industry $[13,14]$ as well as in metallic industries $[15,16]$, this indicates that the use of the quinoxaline derivatives as inhibitors is very interesting $[17,18]$. The high efficiency of these compounds against corrosion can be in their rich molecular structure, which explains the high capability of these molecules to overcome corrosion. Recently, in addition to experimental investigations, the evaluation of inhibition performance is also conducted theoretically by DFT calculation and molecular dynamic simulation studies for the understanding of some experimentally unknown properties, exploring and establishing relationships between inhibitor molecules and the metal surface $[19,20]$. N.A. Al-Mobarak et al. [21] have studied the corrosion inhibition of copper in $3.5 \% \mathrm{NaCl}$ using new pyrimidine derivatives, namely, 2-mercapto-4-(p-methoxyphenyl)-6-oxo-1,6dihydropyrimidine-5-carbonitrile (MPD) by Monte Carlo simulation and theoretical calculation, and all quantum analysis correlated well with electrochemical investigation. In addition, Youguo Yan et al. [22] have applied the DFT method using the GGA/PW91 functional with the double numerical plus $\mathrm{d}$-functions basis set to investigate the adsorption behavior of three purine compounds, $\mathrm{A}, \mathrm{B}$ and $\mathrm{C}$ on the $\mathrm{Fe}\left(\begin{array}{lll}0 & 0 & 1\end{array}\right)$ surface. The theoretical results, including global molecular reactivity descriptors and active sites by Fukui functions analysis well support the order of the IE\%. They also applied molecular dynamic simulation to predict the inhibitive performance of purines studied, the tested molecules adsorbed parallel onto $\mathrm{Fe}\left(\begin{array}{lll}0 & 0 & 1\end{array}\right)$ surface, and the order of interaction energy support the experimental $I E \%$. Using combined quantum chemical and molecular dynamic simulation studies, $\mathrm{S}$. Kr. Saha et al. [23] also studied the adsorption characteristics of two aminobenzonitrile derivatives, $(2-\mathrm{AB})$ and $(3-\mathrm{AB})$ to understand the inhibition mechanism of steel corrosion in acidic medium $(\mathrm{HCl})$.

*Corresponding author: Quraishi MA, Department of Chemistry, Indian Institute of Technology, B.H.U. Varanasi, Uttar Pradesh, India-221005, Tel: 9307025126; E-mail: maquraishi.apc@itbhu.ac.in

Received April 26, 2016; Accepted May 26, 2016; Published June 06, 2016

Citation: Lgaz H, Salghi R, Jodeh S, Ramli Y, Larouj M, et al (2016) Understanding the Adsorption of Quinoxaline Derivatives as Corrosion Inhibitors for Mild Steel in Acidic Medium: Experimental, Theoretical and Molecular Dynamic Simulation Studies. J Steel Struct Constr 2: 111. doi:10.4172/2472-0437.1000111

Copyright: @ 2016 Lgaz H, et al. This is an open-access article distributed under the terms of the Creative Commons Attribution License, which permits unrestricted use, distribution, and reproduction in any medium, provided the original author and source are credited. 
Citation: Lgaz H, Salghi R, Jodeh S, Ramli Y, Larouj M, et al (2016) Understanding the Adsorption of Quinoxaline Derivatives as Corrosion Inhibitors for Mild Steel in Acidic Medium: Experimental, Theoretical and Molecular Dynamic Simulation Studies. J Steel Struct Constr 2: 111. doi:10.4172/2472-0437.1000111

Page 2 of 17

The quantum chemical parameters QCPs reveals that the electron donation and electron acceptance capability of 2-AB and 3-AB are in well accordance with experimental $I E \%$. While, the MD simulation reveals that the distance between active sites and Fe $\left(\begin{array}{lll}1 & 0 & 0\end{array}\right)$ atoms are lying within a range of $3.5 \AA$, indicating that a chemical bonds are formed during the interaction of the inhibitors on the Fe $\left(\begin{array}{lll}1 & 1 & 0\end{array}\right)$ surface. Recently, Z. Zhang et al. [24] applied the radial distribution function (RDF) to study the mechanism of adsorption processes and the synergistic inhibition effect between indigo carmine and three cationic molecules on CS, in an acidic solution. The researchers reported that the bonding length of all heteroatoms-Fe and carbons-Fe are less than $3.5 \AA$, suggesting that the adsorption of indigo carmine and their cationic molecules occur mainly by these atoms. In addition, Si-Wei Xie et al. [25] also introduced the RDF accompanying with DFT and experimental studies to investigate the inhibitive performance of 3,5-dibromo salicylaldehyde Schiff 's base. The results obtained revealed that $\mathrm{C}, \mathrm{N}, \mathrm{O}$ and $\mathrm{S}$ atoms of three studied inhibitors are the most reactive sites responsible of efficiency of the tested compound. This work aims to evaluate the inhibitory properties and adsorption characteristics of three synthetic quinoxaline derivatives of the MS in 1.0 $\mathrm{M} \mathrm{HCl}$, using the weight loss (WL), electrochemical techniques (EIS and PDP) and surface examination by SEM. Quantum chemical parameters (QCPs) by DFT method and Monte Carlo simulation accompanying with radial distribution function (RDF) of the (E)-3styrylquinoxalin-2(1H)-one (STQ), (E)-1-benzyl-3-(4-methoxystyryl) quinoxalin-2(1H)-one (BMQ) and (E)-3-(2-(furan-2-yl) vinyl) quinoxalin-2(1H)-one (FVQ) were calculated and discussed.

\section{Data and Method}

\section{Inhibitors preparation}

The tested inhibitors, namely (E)-3-styrylquinoxalin-2(1H)one (STQ), (E)-1-benzyl-3-(4-methoxystyryl)quinoxalin-2(1H)-one (BMQ) and (E)-3-(2-(furan-2-yl)vinyl)quinoxalin-2(1H)-one (FVQ) were synthesized according to this experimental procedure:

The bibliography reports various methods to prepare styrylquinoxalines [26,27]. For our part, we suggested a different synthetic route which comprised reacting fusion 3-méthtylquinoxaline2-one with aromatic aldehydes. This method was carried out in the absence of solvent. We had a possibility to isolate the desired compound in a yield of around $80 \%$ (Scheme 1). Indeed, $6.25 \mathrm{mmol}$ of 3-méthylquinoxalin-2-one was fused with $12.5 \mathrm{mmol}$ of the benzaldehyde for 2 hours, at the boiling temperature of the latter. At the end of the reaction, the solid compound is allowed to cool and then heated at $100^{\circ} \mathrm{C}$ for 10 minutes in $50 \mathrm{ml}$ of ethanol. The product is filtered hot then washed with ethanol $[5,28]$ (Scheme 1).

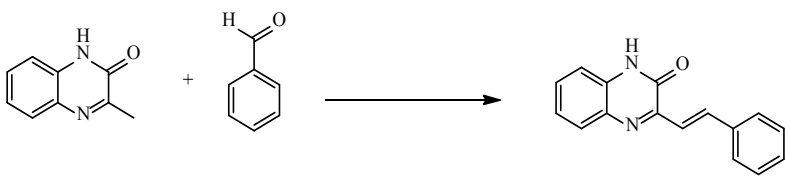

Schema 1: Synthesis of (E)-3-styrylquinoxalin-2(1H)-one (STQ).

To a solution of (E)-3-(4-methoxystyryl)quinoxalin-2(1H)one in $20 \mathrm{ml}$ of dimethyl formaldehyde was added (chloromethyl) benzene $(0.85 \mathrm{ml}), \mathrm{K} 2 \mathrm{CO} 3 \quad(1 \mathrm{~g})$ and catalytic amount of tetrabutylammoniumbromide. The mixture was stirred at room temperature for $24 \mathrm{~h}$. Then the solvent was remove under reduce pressure, the residue was crystallized in ethanol to afford the (E)-1allyl-3-(4-methoxystyryl) quinoxalin-2(1H)-one [29]. (Scheme 2).

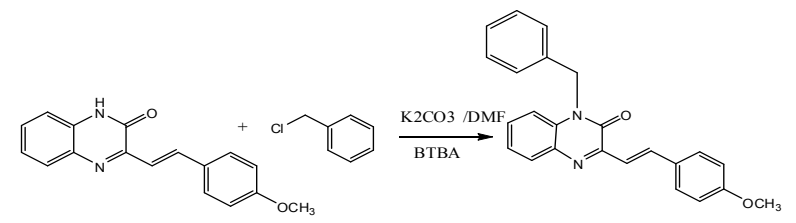

Schema 2: Synthesis of (E)-1-benzyl-3-(4-methoxystyryl) quinoxalin2(1H)-one (BMQ).

$6.25 \mathrm{mmol}$ of 3-methylquinoxalin-2(1H)-one was merged with 12.5 mmol of the furan-2-carbaldehyde for $2 \mathrm{~h}$, at the boiling temperature of the latter. At the end of the reaction, the solid was allowed to cool and then heated to $100^{\circ} \mathrm{C}$ for $10 \mathrm{~min}$ in $50 \mathrm{ml}$ of ethanol. The product was filtered hot and washed with ethanol (Scheme 3).

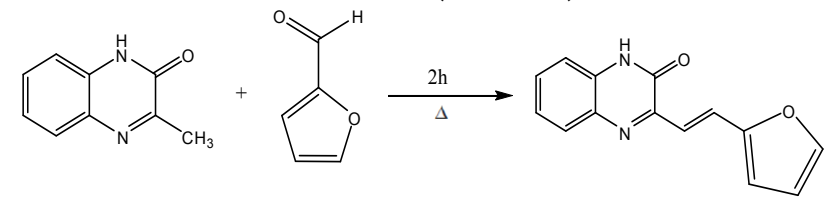

Schema 3: Synthesis of (E)-3-(2-(furan-2-yl) vinyl) quinoxalin2(1H)-one (FVQ).

Electrolytic solution and concentration range: Acid solutions (1.0 $\mathrm{M} \mathrm{HCl}$ ) were prepared by diluting a reagent of analytical grade $\mathrm{HCl} 37 \%$ (from Sigma-Aldrich) with double-distilled water. The concentration range of the quinoxaline derivatives used was 2 to $8 \mathrm{mM}$.

Weight loss tests, electrochemical measurements and surface observation: In this study, the effects of quinoxaline derivatives (BMQ, FVQ and STQ) on the metal corrosion were performed by the electrochemical measurements (EIS and polarization curves), and weight loss (WL) tests (temperature range of 303 to $333 \mathrm{~K}$ ). The detail of experiments referenced from the published article of Rachid Salghi et al. $[4,30,31]$.

Molecular modeling and dynamic simulations: All quantum chemical calculations of quinoxaline derivatives were performed at the DFT/B3LYP level of theory using 6-31G (d, p) basis set with Gassian03 program [32-35]. The adsorption configuration of BMQ, FVQ and STQ on iron surface were dynamically simulated by using the Adsorption Locator module of the Materials Studio 6.0 software from Accelrys Inc [36]. The Fe crystal was chosen to represent the MS surface. First the crystal was cleaved along the ( $\left.\begin{array}{lll}1 & 1 & 0\end{array}\right)$ plane, as it is the most stable surface as reported in the literature [37]. Then, the Fe (lll 110$)$ plane was subsequently enlarged into an appropriate supercell to provide a large surface for the interaction of the inhibitor. The interaction between BMQ, FVQ, STQ and Fe surface was assumed in a simulation box $(29.78 \times 29.78 \times 60.13 \AA)$ with periodic boundary conditions. After that, thickness of the vacuum slab was $50 \AA$. COMPASS force field was chosen to optimize the structures of all components of the system of interest. More detail of MC simulation is referenced from the published articles $[37,38]$.

\section{Results and Discussion}

\section{Weight loss measurement}

Effect of concentration and temperature: The inhibitive efficiency calculated by the Eq. (1) of BMQ, FVQ and STQ in the corrosive medium of the MS was carried out after immersion for $6 \mathrm{~h}$ at 303 to $333 \mathrm{~K}$, in all studied concentrations by weight loss measurements. The results are presented in Table 1 and Figure 1 (Similar plots obtained for 313-333 K, but not presented in this article). 


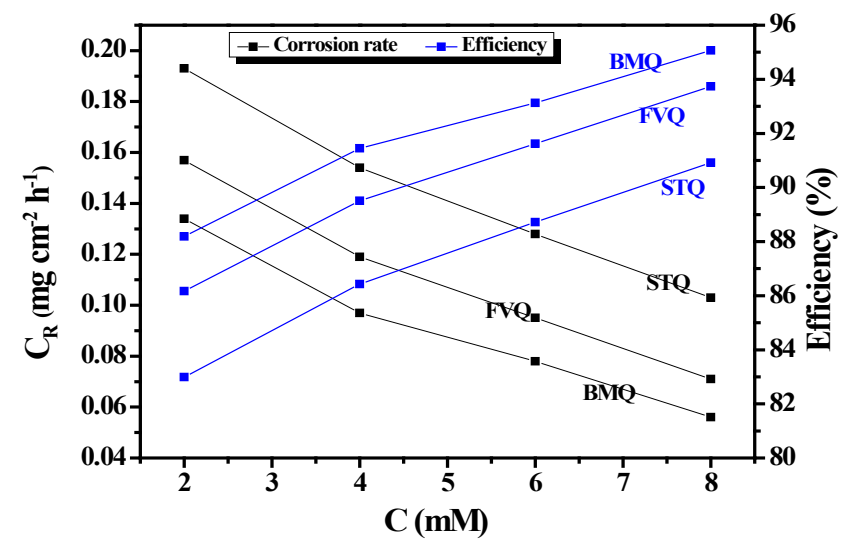

Figure 1: Relationship between the inhibition efficiency, corrosion rate and inhibitors concentration for MS after $6 \mathrm{~h}$ immersion in $1.0 \mathrm{M} \mathrm{HCl}$ at $303 \mathrm{~K}$.

\begin{tabular}{|c|c|c|c|c|c|c|c|}
\hline \multirow{3}{*}{$\begin{array}{l}\text { Temp. } \\
\text { (K) }\end{array}$} & \multirow{3}{*}{$\begin{array}{c}\text { Concentration } \\
(\mathrm{mM})\end{array}$} & \multicolumn{2}{|c|}{ BMQ } & \multicolumn{2}{|c|}{ FVQ } & \multicolumn{2}{|c|}{ STQ } \\
\hline & & $C_{R}$ & $\eta_{w}$ & $C_{R}$ & $\eta_{w}$ & $C_{R}$ & $\eta_{w}$ \\
\hline & & $\begin{array}{c}(\mathrm{mg} \\
\mathrm{cm}^{-2} \\
\left.\mathrm{~h}^{-1}\right)\end{array}$ & $(\%)$ & $\begin{array}{c}(\mathrm{mg} \\
\mathrm{cm}^{-2} \\
\left.\mathrm{~h}^{-1}\right)\end{array}$ & $(\%)$ & $\begin{array}{c}(\mathrm{mg} \\
\mathrm{cm}^{-2} \\
\left.\mathrm{~h}^{-1}\right)\end{array}$ & (\%) \\
\hline & Blank & 1.135 & - & - & - & - & - \\
\hline \multirow[t]{5}{*}{303} & 8 & 0.056 & 95.07 & 0.071 & 93.74 & 0.103 & 90.92 \\
\hline & 6 & 0.078 & 93.13 & 0.095 & 91.62 & 0.128 & 88.72 \\
\hline & 4 & 0.097 & 91.45 & 0.119 & 89.51 & 0.154 & 86.43 \\
\hline & 2 & 0.134 & 88.19 & 0.147 & 87.04 & 0.174 & 84.66 \\
\hline & Blank & 2.466 & - & - & - & - & - \\
\hline \multirow[t]{5}{*}{313} & 8 & 0.157 & 93.63 & 0.201 & 91.85 & 0.311 & 87.39 \\
\hline & 6 & 0.197 & 92.01 & 0.262 & 89.37 & 0.361 & 85.36 \\
\hline & 4 & 0.293 & 88.12 & 0.343 & 86.09 & 0.426 & 82.72 \\
\hline & 2 & 0.341 & 86.17 & 0.385 & 84.38 & 0.501 & 79.68 \\
\hline & Blank & 5.032 & - & - & - & - & - \\
\hline \multirow[t]{5}{*}{323} & 8 & 0.446 & 91.14 & 0.521 & 89.65 & 0.794 & 84.22 \\
\hline & 6 & 0.546 & 89.15 & 0.647 & 87.14 & 0.898 & 82.15 \\
\hline & 4 & 0.765 & 84.79 & 0.801 & 84.08 & 1.058 & 78.97 \\
\hline & 2 & 0.897 & 82.17 & 1.008 & 79.96 & 1.178 & 76.59 \\
\hline & Blank & 10.029 & - & - & - & - & - \\
\hline \multirow[t]{4}{*}{333} & 8 & 1.192 & 88.11 & 1.527 & 84.77 & 1.812 & 81.93 \\
\hline & 6 & 1.388 & 86.16 & 1.758 & 82.47 & 2.081 & 79.25 \\
\hline & 4 & 1.793 & 82.12 & 2.196 & 78.1 & 2.345 & 76.62 \\
\hline & 2 & 2.329 & 76.77 & 2.532 & 74.75 & 2.901 & 71.07 \\
\hline
\end{tabular}

Table 1: $C_{R}$ and $\eta_{w} \%$ obtained from weight loss measurements of MS in $1 \mathrm{M} \mathrm{HCl}$ containing various concentrations of $B M Q, F V Q$ and $S T Q$ at different temperatures.

$$
\eta_{w}(\%)=\frac{C_{R}-C_{R(i n h)}}{C_{R}} \times 100
$$

$\mathrm{C}_{\mathrm{R}}$ and $\mathrm{C}_{\mathrm{R}(\mathrm{inh})}$ are the corrosion rates in the absence and presence of BMQ, FVQ and STQ, respectively.

Prominent decrease of the $C_{R}$ observed because of the addition of various concentrations of quinoxaline derivatives, while the $I E \%$ increases with increasing the concentration of tested inhibitors at the range of studied temperature. Over temperature increase the $I E \%$ of our molecules is reduced due to partial desorption of studied compounds. The $I E \%$ values of BMQ decreased slowly $(95.07 \%$ to $88.19 \%$ in $8 \mathrm{mM})$ compared with those of FVQ and STQ $\left(\eta_{\mathrm{w}} \%\right.$ reduced to $86.17 \%$ for FVQ and $82.99 \%$ for STQ) following the order: BMQ $>$ FVQ $>$ STQ. This can be attributed to the difference in molecular size of quinoxaline compounds. The high protection of our molecules is due to their adsorption on steel surface, which decreases the fatal effect of aggressive medium.

Activation parameters: The inhibitive mechanism can be understood based on the thermodynamic and activation parameters. From Table 1, it can be observed that $C_{R}$ depends on temperature for all inhibitor concentrations. The $\mathrm{C}_{\mathrm{R}}$ is related to the temperature by the following Eqs. $(2,3)$ [39]:

$$
\begin{aligned}
& C_{R}=k \exp \left(\frac{-E_{a}}{R T}\right) \\
& C_{R}=\frac{R T}{N h} \exp \left(\frac{\Delta S_{a}}{R}\right) \exp \left(-\frac{\Delta H_{a}}{R T}\right)
\end{aligned}
$$

where, $E_{a}$ is the activation energy, $\Delta S_{a}$ is the change in entropy of activation, $\Delta H_{a}$ is the change in enthalpy of activation, $\mathrm{k}$ is the Arrhenius pre-exponential factor, $\mathrm{h}$ is Planck's constant, $\mathrm{N}$ is Avogadro's number, $\mathrm{T}$ is the absolute temperature and $\mathrm{R}$ is the universal gas constant.

Using Eq. (2) a plot of $\ln C_{R}$ versus $1 / T$ were drawn to get a straight line (Figure 2), from the values of slope and intercept, the values of $E_{a}$ were calculated for three inhibitors at various concentrations. Using Eq. (3), another linear plot of $\ln \mathrm{C}_{\mathrm{R}} / \mathrm{T}$ versus $1 / \mathrm{T}$ was drawn (Figure 3) with slope $\left(-\Delta H_{a} / \mathrm{R}\right)$ and intercept $\left[\ln (\mathrm{R} / \mathrm{Nh})+\Delta S_{a} / \mathrm{R}\right]$, which were used for the calculation of $\Delta \mathrm{Ha}$ and $\Delta \mathrm{Sa}$. All the values are listed in Table 2. We can be find from Table 2 that the $\mathrm{Ea}$ (Inh) $>\mathrm{Ea}$ (Blank), which can be explained by the physical adsorption of quinoxaline molecules [40]. For three inhibitors, the value of the activation energy to take up higher maximum for the higher concentrations; and generally follows the order of $\mathrm{Ea}(\mathbf{B M Q})>\mathrm{Ea}(\mathbf{F V Q})>\mathrm{Ea}(\mathbf{S T Q})$, this order is in good agreement with the order of inhibition efficiencies, that decreased with the increase of the temperature. In the same case, Saranya et al. [17] studied the inhibition effect of Acenaphtho[1,2-b] quinoxaline on the MS dissolution in acidic environment, the effect of temperature study reveals that the $I E \%$ decrease with the increase of the temperature and the $E_{a}$ value decrease remarkably than the value obtained in blank solution, which in good correlation with our investigation (Figure 4).

The positive sign of the enthalpy (Table 2) reflects the endothermic nature of the MS dissolution process. While the higher values of $\Delta \mathrm{Sa}$ in presence of investigated compounds compared to those calculated from the uninhibited solution might be the result of the adsorption of quinoxaline derivatives from the aggressive solution, which could be regarded as a quasi-substitution process between inhibitor molecules in the aqueous phase and water molecules on the MS surface $[41,42]$.

\section{Adsorption isotherm and thermodynamic parameters}

On the basis of evaluation of the interaction between the inhibitors and steel surface, it is important to consider the adsorption isotherms to analyze the mechanism and nature of the adsorption processes of chemicals species on the MS surface [43]. For additional information about the compounds tested, several types of adsorption isotherms carried out such as Frumkin (Eq. 4), Temkin (Eq. 5), Freundlich (Eq. 6) and Langmuir (Eq. 7) among which the Langmuir isotherm showed the best fit with regression coefficient $\left(R^{2}\right)$ values close to unity for all tested compounds. Considering a sufficient time for adsorption equilibrium, the fractional surface coverage $(\mathbb{\otimes})$ can be easily calculated by $\eta_{w}(\%) / 100$ from weight loss tests $[44]$ : 
Citation: Lgaz H, Salghi R, Jodeh S, Ramli Y, Larouj M, et al (2016) Understanding the Adsorption of Quinoxaline Derivatives as Corrosion Inhibitors for Mild Steel in Acidic Medium: Experimental, Theoretical and Molecular Dynamic Simulation Studies. J Steel Struct Constr 2: 111. doi:10.4172/2472-0437.1000111
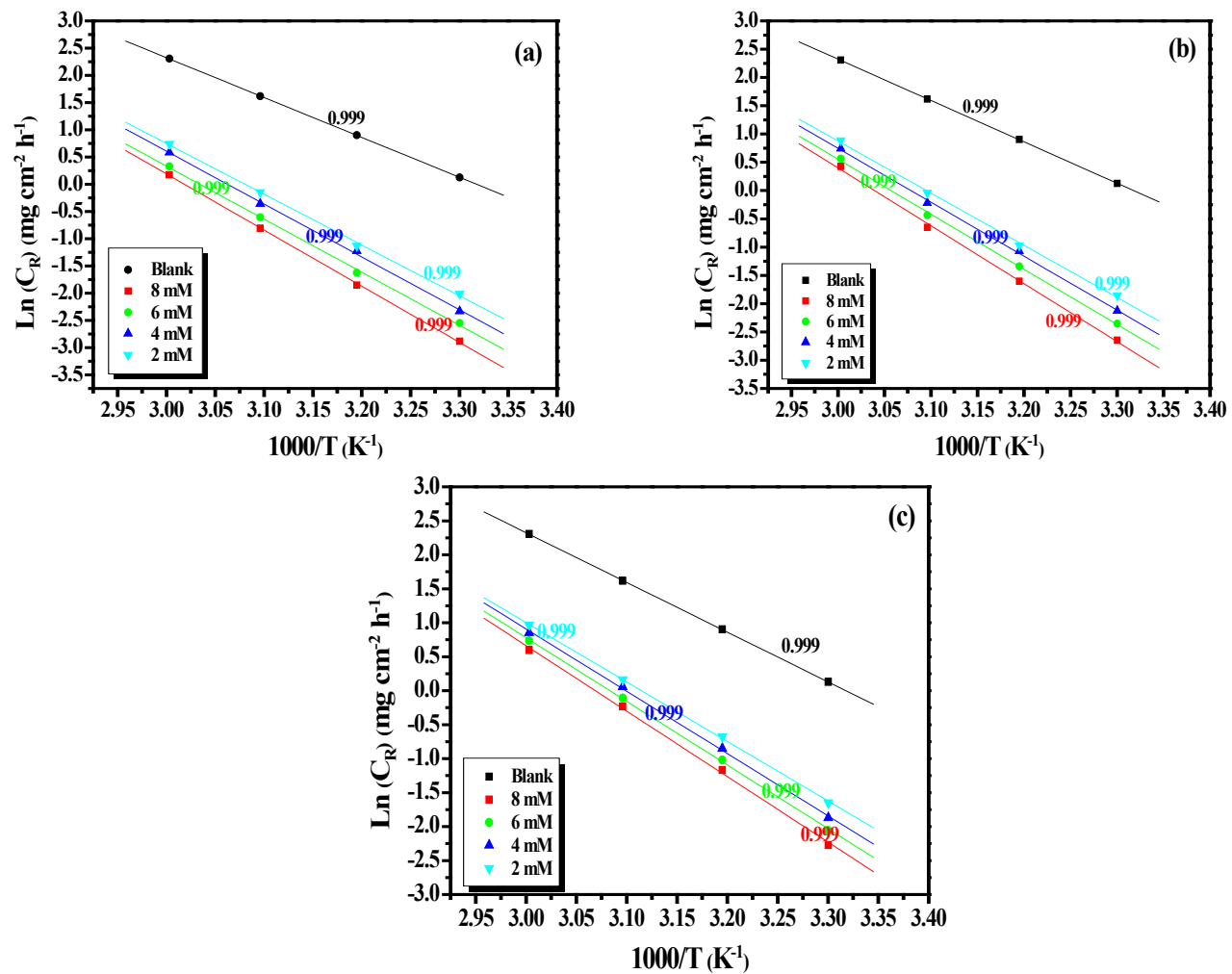

Figure 2: Arrhenius plots for the $\mathrm{MS}$ in $1.0 \mathrm{M} \mathrm{HCl}$ in the absence and presence of different concentrations of (a) BMQ (b) FVQ and (c) STQ at different temperatures.
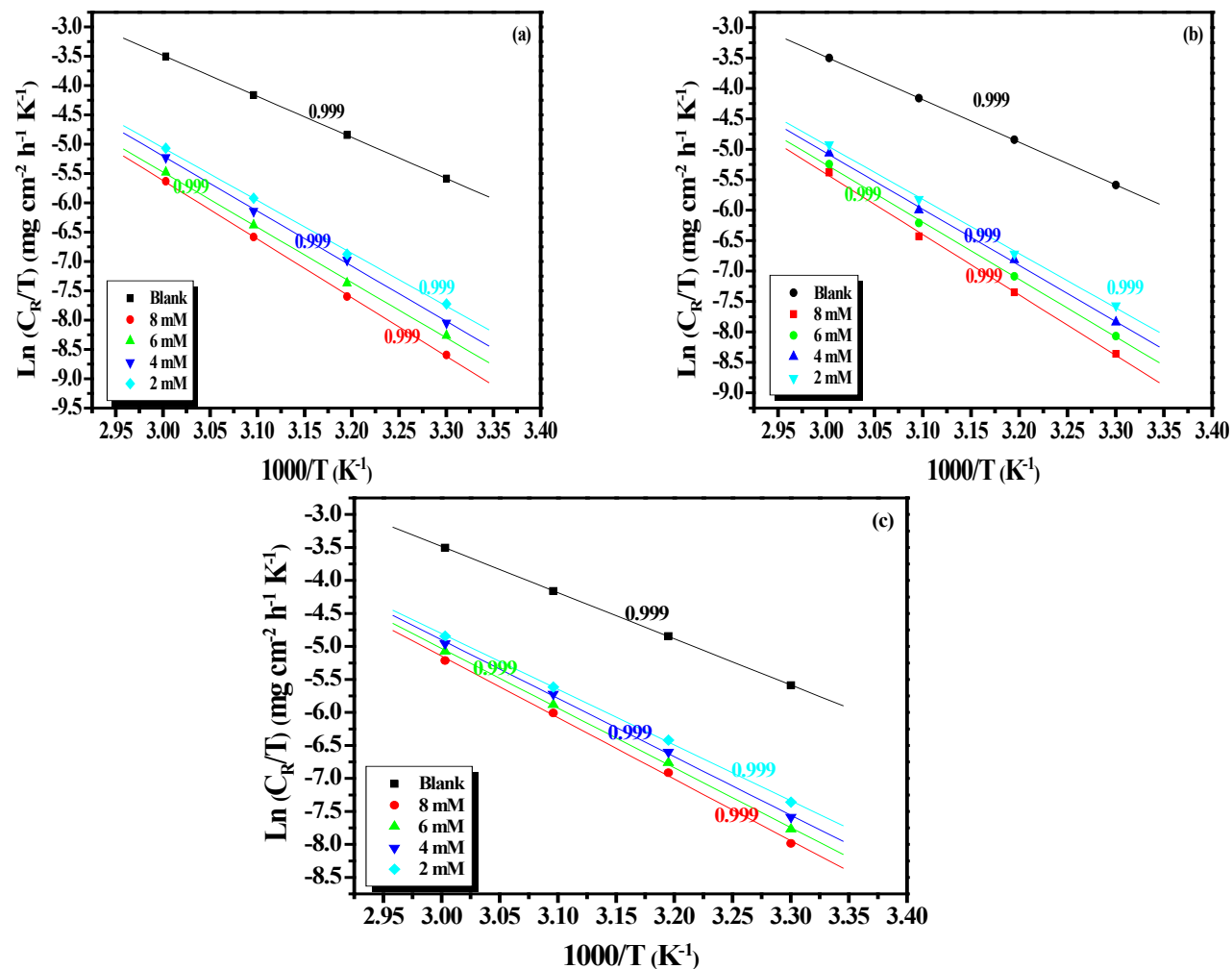

Figure 3: Transition state plots for the inhibition of corrosion of the MS in $1.0 \mathrm{M} \mathrm{HCl}$ in the absence and presence of different concentrations of (a) BMQ (b) FVQ and (c) STQ at different temperatures. 

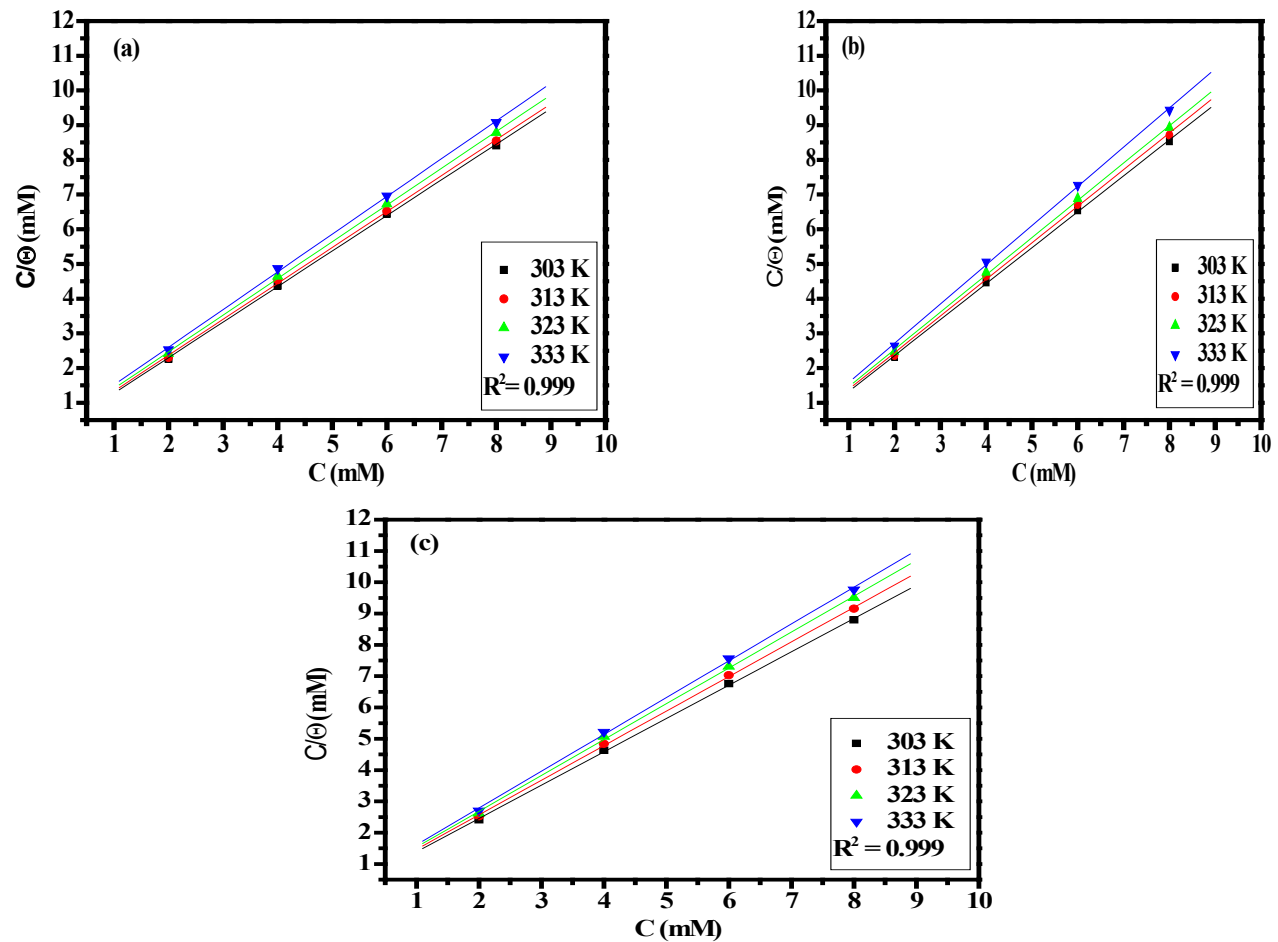

Figure 4: Langmuir adsorption isotherm on the MS in $1.0 \mathrm{M} \mathrm{HCl}$ at different temperatures of (a) BMQ (b) FVQ and (c) STQ

\begin{tabular}{|c|c|c|c|c|c|}
\hline Inhibitors & $\begin{array}{c}\text { Concentration } \\
\text { (mM) }\end{array}$ & $\begin{array}{c}\text { Ea } \\
\left(\mathrm{kJ} \mathrm{mol}^{-1}\right)\end{array}$ & $\begin{array}{l}\Delta \mathrm{Ha} \\
\left(\mathrm{kJ} \mathrm{mol}^{-1}\right)\end{array}$ & $\begin{array}{l}\Delta \mathrm{Sa} \\
\left(\mathrm{KJ} \mathrm{mol}^{-1} \mathrm{~K}^{-1}\right)\end{array}$ & Ea- $\Delta \mathrm{Ha}$ \\
\hline Blank & - & 60.79 & 58.15 & -51.84 & 2.64 \\
\hline \multirow{4}{*}{ BMQ } & 8 & 85.65 & 83.01 & 5.07 & 2.64 \\
\hline & 6 & 80.92 & 78.28 & -8.04 & 2.64 \\
\hline & 4 & 80.68 & 78.04 & -6.46 & 2.64 \\
\hline & 2 & 77.44 & 74.80 & -15.01 & 2.64 \\
\hline \multirow{4}{*}{ FVQ } & 8 & 85.10 & 82.46 & 5.05 & 2.64 \\
\hline & 6 & 80.94 & 78.30 & -6.10 & 2.64 \\
\hline & 4 & 79.30 & 76.66 & -9.43 & 2.64 \\
\hline & 2 & 76.66 & 74.02 & -16.28 & 2.64 \\
\hline \multirow{4}{*}{ STQ } & 8 & 80.09 & 77.45 & -7.78 & 2.64 \\
\hline & 6 & 77.84 & 75.20 & -13.54 & 2.64 \\
\hline & 4 & 76.20 & 73.56 & -17.41 & 2.64 \\
\hline & 2 & 72.72 & 70.08 & -27.05 & 2.64 \\
\hline
\end{tabular}

Table 2: Activation parameters for $\mathrm{MS}$ corrosion in $1.0 \mathrm{M} \mathrm{HCl}$ in the absence and presence of different concentrations of BMQ, FVQ and STQ at different temperatures.

$$
\begin{aligned}
& \theta=\frac{1}{f} \ln \left(K_{a d s} \frac{C(1-\theta)}{C}\right) \\
& \theta=\frac{1}{f} \ln \left(K_{a d s} C\right) \\
& \theta=K_{a d s} C \\
& \frac{C}{\theta}=\frac{1}{K_{a d s}}+C
\end{aligned}
$$

Where: $\mathrm{C}$ is the concentration of inhibitors in the electrolyte, $\mathrm{K}_{\mathrm{ads}}$ is the equilibrium constant for the adsorption-desorption process, $\theta$ is the surface coverage and $\mathrm{f}$ is the molecular interaction constant. The values of $\mathrm{K}_{\text {ads }}$ can be calculated from the intercepts of the straight lines $\mathrm{C}_{\text {inh }} / \theta$-axis. The $\mathrm{K}_{\text {ads }}$ related to the standard free energy of adsorption $\Delta G_{a d s}^{\circ}$ by following Eq. (8):

$$
\Delta G_{a d s}^{\circ}=-R T \ln \left(C_{\text {solvent }} x K_{a d s}\right)
$$

Where: $C_{\text {solvent }}$ is the molar concentration of solvent $\left(\right.$ For $\mathrm{H}_{2} \mathrm{O}$ is $\left.55.5 \mathrm{~mol} \mathrm{~L}^{-1}\right), \mathrm{T}$ is the absolute temperature. The $\mathrm{K}_{\mathrm{ads}}$ and $\Delta G_{a d s}^{\mathrm{o}^{2}}$ values calculated and collected in Table 3 . The values of $K_{\text {ads }}$ could take as an indication of the adsorption ability of BMQ, FVQ and STQ on the steel surface. On the other hand, the $\mathrm{K}_{\mathrm{ads}}$ values follow the order: $\mathrm{K}_{\text {ads }}($ BMQ $)>\mathrm{K}_{\text {ads }}(\mathbf{F V Q})>\mathrm{K}_{\text {ads }}($ STQ $)$. This further confirms that $\mathrm{n}_{\mathrm{w}}$ (\%) decreases with the increase in temperature and the better inhibitive performance of BMQ than the others compounds. The negative values of $\Delta G_{a d s}^{\circ}$ imply that the adsorption was spontaneous and the stability of the adsorbed film on the MS surface [45]. All the $\Delta G_{a d s}^{\circ}$ values are around $-13 \mathrm{~kJ} / \mathrm{mol}$. normally; the physical adsorption is correlated with the absolute values of $\Delta \mathrm{G}^{\circ}$ around $20 \mathrm{~kJ} / \mathrm{mol}$ or lower, and a value of $\Delta G_{a d s}$ up to $40 \mathrm{~kJ} / \mathrm{mol}$ or more negative is an indication of the chemical adsorption [46,47]. The $\Delta G_{a d s}$ values in Table 3 indicate clearly the physical adsorption of tested compounds on the MS surface. In the literature, we can find in the investigation of Obot et al. [17] that the 2,3-Diphenylbenzoquinoxaline interact with the MS in the same way in sulphuric acid, the authors reported that the $\Delta G_{a d s}^{\circ}$ is $-11.4 \mathrm{~kJ} \mathrm{~mol}^{-1}$, which explained by the electrostatic interaction with tested quinoxaline derivative and the MS surface. The $\Delta \mathrm{H}_{\text {ads }}$ and $\Delta \mathrm{S}_{\text {ads }}$ calculated by the following Eq. (9):

$$
\ln K_{a d s}=\ln \frac{1}{55.5}-\frac{\Delta H_{a d s}^{\circ}}{R T}+\frac{\Delta S_{a d s}^{\circ}}{R}
$$


Citation: Lgaz H, Salghi R, Jodeh S, Ramli Y, Larouj M, et al (2016) Understanding the Adsorption of Quinoxaline Derivatives as Corrosion Inhibitors for Mild Steel in Acidic Medium: Experimental, Theoretical and Molecular Dynamic Simulation Studies. J Steel Struct Constr 2: 111. doi:10.4172/2472-0437.1000111

The values of $\Delta \mathrm{H}_{\mathrm{ads}}$ and $\Delta \mathrm{S}_{\mathrm{ads}}$ are collected in Table 3, more information of the corrosion process and nature of adsorption can be obtained on the basis of the values of $\Delta H_{a d s}^{\circ}$ of investigated compounds. The $\Delta H_{a d s}^{\circ}$ values of quinoxaline derivatives are negative, indicating the exothermic process of adsorption of studied inhibitors. The endothermic adsorption process $\Delta H_{a d s}^{\circ}>0$ is correlated to chemical adsorption, while the exothermic adsorption process $\Delta H_{a d s}^{\circ}<0$ is attributed to physical, chemical or mixture adsorption [48]. In an exothermic process, the physisorption process is correlated with the values of $\Delta H_{a d s}^{\circ}$ lower than $40 \mathrm{~kJ} \mathrm{~mol}^{-1}$. Whereas, chemical adsorption is for $\Delta H_{a d s}^{\circ}$ values around $100 \mathrm{~kJ} \mathrm{~mol}^{-1}$. In this investigation, $\Delta H_{a d s}^{\circ}$ values of all quinoxalines derivatives are less than $40 \mathrm{~kJ} \mathrm{~mol}^{-1}$, suggesting that the physical adsorption may occur during the interaction between the tested compounds and the MS surface. The negative values of $\Delta S_{a d s}$ indicates that before the adsorption of inhibitor's molecules on the MS surface, inhibitor molecules might freely move in the bulk solution, but with the progress in the adsorption of BMQ, FVQ and STQ, inhibitors molecules were orderly adsorbed on the MS surface, as a result a decrease in entropy is observed [49]. Based on the thermodynamic principles, it can be noted that since the adsorption is an exothermic process, it must be accompanied by a decrease of entropy [50].

\section{Potentiodynamic polarization study}

The polarization experiments were undertaken to distinguish the behavior of the corrosion of the MS with and without studied concentrations of BMQ, FVQ and STQ at $303 \mathrm{~K}$. The Tafel plots and the derived parameters are presented in Figures $5 \mathrm{a}-5 \mathrm{c}$ and Table 4, respectively. The $I E \%$ is calculated using the following Eq. (10) [51,52]:

$$
\eta_{P D P}(\%)=\frac{I_{\text {corr }}-I_{\text {corr }(i)}}{I_{\text {corr }}} \times 100
$$

Where $I_{\text {corr }}$ and $I_{\text {corr }(i)}$ are the corrosion current densities for the $\mathrm{MS}$ in $1.0 \mathrm{M} \mathrm{HCl}$ and in $1.0 \mathrm{M} \mathrm{HCl}$ with various concentrations of the tested compounds, respectively.

It can be observed from Figures $5 \mathrm{a}-5 \mathrm{c}$, that the addition of quinoxaline derivatives caused a decrease in the anodic and cathodic current densities with slight shifting of the corrosion potential ( $E_{\text {corr }}$ ), indicating that the quinoxaline derivatives investigated are mixed type inhibitors $[53,54]$. The small change of the constant cathodic Tafel slope, $\beta c$, suggests that the mechanism of proton discharge reaction does not modify by addition of quinoxaline derivatives $[55,56]$. From Table 4, it can be found that the increase of the concentration of our molecules result in a considerable decrease of the $I_{\text {corr }}$ values. In the same trend, a remarkable increase of the $I E \%$ is observed when increasing the inhibitors concentration reaching a maximum value at 8 $\mathrm{mM}$ in the three quinoxaline derivatives studied. It is also evident that BMQ presents the better performance than other inhibitors, which can be correlated to the difference of the structure of the three inhibitors molecules (Figure 6).

\section{AC impedance study}

Nyquist plots of the MS in acidic solutions with and without various concentrations of STQ, FVQ and BMQ at $303 \mathrm{~K}$ after $30 \mathrm{~min}$ of immersion are given in Figures $7 \mathrm{a}-7 \mathrm{c}$. Which a single capacitive loop is clearly observed over the frequency range studied [57,58]. Also appearing are depressed Nyquist plots into the real axis and imperfect semicircles, what can explained by the non-homogeneity and roughness of the MS surface [59]. As previously reported for steel/ acid interface, the EIS data obtained was fitted using the Rs(CPE/ Rct) equivalent circuit (Figures 8 and 9) [60], where Rs is the solution

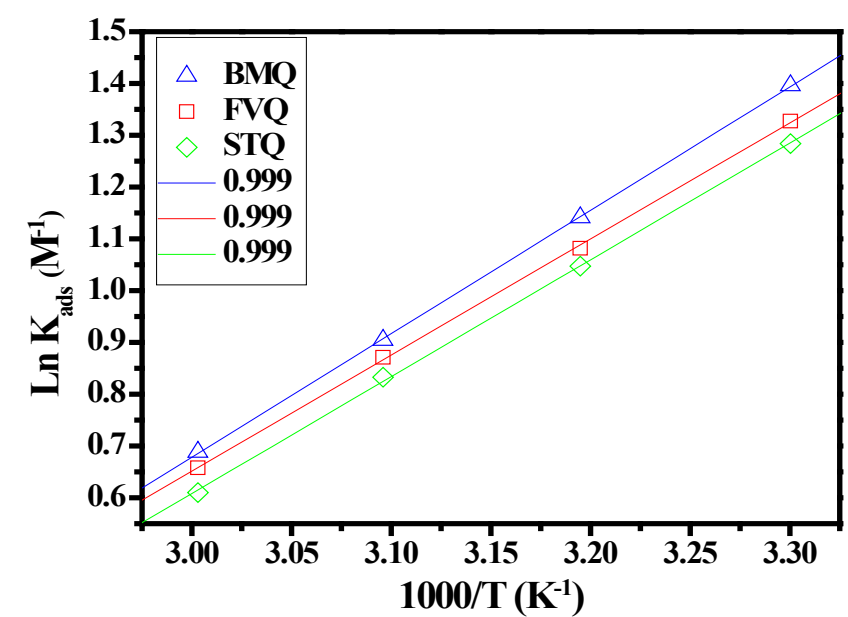

Figure 5: Plots of Ln $K_{\text {ads }}$ vs $1 / T$ for the inhibition of corrosion of MS in $1.0 \mathrm{M}$ $\mathrm{HCl}$ with inhibitors.

\begin{tabular}{|c|c|c|c|c|c|}
\hline Inhibitors & $\begin{array}{c}\text { Temperature } \\
\text { (K) }\end{array}$ & $\begin{array}{l}K_{\text {ads }} \\
\left(M^{-1}\right)\end{array}$ & $\underset{\left(\mathrm{kJ} \mathrm{mol}^{-1}\right)}{\Delta G_{\text {ads }}}$ & $\begin{array}{c}\Delta H_{\text {ads }} \\
\left(\mathrm{kJ} \mathrm{mol}^{-1}\right)\end{array}$ & $\begin{array}{c}\Delta S_{\text {ads }} \\
\left(\mathrm{J} \mathrm{mol}^{-1} \mathrm{~K}^{-1}\right)\end{array}$ \\
\hline \multirow{4}{*}{ BMQ } & 303 & 4.04 & -13.62 & \multirow{4}{*}{-19.81} & \multirow{4}{*}{-20.41} \\
\hline & 313 & 3.13 & -13.41 & & \\
\hline & 323 & 2.47 & -13.21 & & \\
\hline & 333 & 1.99 & -13.01 & & \\
\hline \multirow{4}{*}{ FVQ } & 303 & 3.77 & -13.45 & \multirow{4}{*}{-18.61} & \multirow{4}{*}{-17.04} \\
\hline & 313 & 2.95 & -13.26 & & \\
\hline & 323 & 2.39 & -13.11 & & \\
\hline & 333 & 1.93 & -12.93 & & \\
\hline \multirow{4}{*}{ STQ } & 303 & 3.61 & -13.34 & \multirow{4}{*}{-18.59} & \multirow{4}{*}{-17.81} \\
\hline & 313 & 2.85 & -13.17 & & \\
\hline & 323 & 2.30 & -13.01 & & \\
\hline & 333 & 1.84 & -12.80 & & \\
\hline
\end{tabular}

Table 3: Adsorption parameters of BMQ, FVQ and STQ for mild steel corrosion in $1.0 \mathrm{M} \mathrm{HCl}$ at different temperatures.

\begin{tabular}{|c|c|c|c|c|c|c|}
\hline Inhibitor & $\begin{array}{c}\text { Concentration } \\
(\mathrm{mM})\end{array}$ & $\begin{array}{c}-E_{\text {corr }} \\
\text { (mV/SCE) }\end{array}$ & $\begin{array}{c}-\beta c \\
(\mathrm{mV} \\
\left.\mathrm{dec}^{-1}\right)\end{array}$ & $\begin{array}{c}\mathrm{I}_{\text {corr }} \\
\left(\mu \mathrm{A} \mathrm{cm}^{-2}\right)\end{array}$ & $\begin{array}{l}\eta_{\text {Tafel }} \\
(\%)\end{array}$ & $\theta$ \\
\hline Blank & 1.0 & 496 & 150.19 & 564 & - & - \\
\hline \multirow{4}{*}{ BMQ } & 8 & 499 & 146.79 & 20.98 & 96.28 & 0.9628 \\
\hline & 6 & 525 & 145.61 & 38.12 & 93.24 & 0.9324 \\
\hline & 4 & 532 & 144.60 & 56.21 & 90.03 & 0.9003 \\
\hline & 2 & 539 & 147.00 & 68.04 & 87.94 & 0.8794 \\
\hline \multirow{4}{*}{ FVQ } & 8 & 513 & 145.34 & 30.08 & 94.67 & 0.9467 \\
\hline & 6 & 530 & 146.66 & 50.67 & 91.01 & 0.9101 \\
\hline & 4 & 544 & 141.37 & 71.59 & 87.31 & 0.8731 \\
\hline & 2 & 555 & 147.73 & 85.18 & 84.90 & 0.8490 \\
\hline \multirow{4}{*}{ STQ } & 8 & 526 & 135.19 & 47.03 & 91.66 & 0.9166 \\
\hline & 6 & 539 & 134.24 & 59.32 & 89.48 & 0.8948 \\
\hline & 4 & 552 & 137.27 & 88.00 & 84.40 & 0.8440 \\
\hline & 2 & 547 & 139.13 & 106.04 & 81.20 & 0.8120 \\
\hline
\end{tabular}

Table 4: Corrosion parameters for corrosion of MS with selected concentrations of the inhibitors in $1.0 \mathrm{M} \mathrm{HCl}$ by potentiodynamic polarization method at $303 \mathrm{~K}$.

resistance, $\mathrm{R}_{\mathrm{ct}}$ denotes that the charge-transfer resistance and CPE is "constant phase element". The introduction of CPE was necessitated to compensate deviations from ideal capacitor due to distributed surface heterogeneity. The impedance of this element is frequency-dependent and can be calculated using the Eq. (11) $[61,62]$ : 
Citation: Lgaz H, Salghi R, Jodeh S, Ramli Y, Larouj M, et al (2016) Understanding the Adsorption of Quinoxaline Derivatives as Corrosion Inhibitors for Mild Steel in Acidic Medium: Experimental, Theoretical and Molecular Dynamic Simulation Studies. J Steel Struct Constr 2: 111. doi:10.4172/2472-0437.1000111
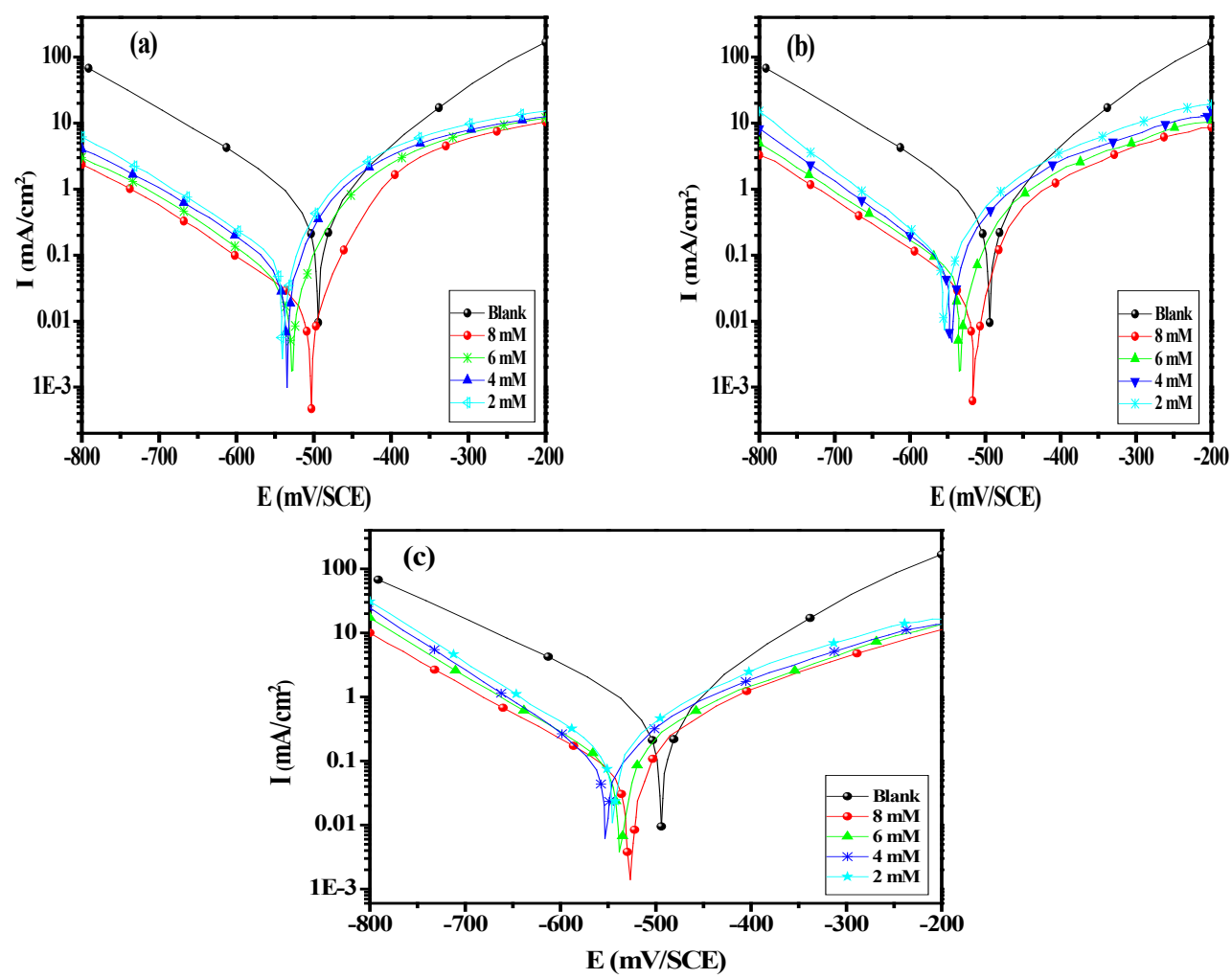

Figure 6: Polarisation curves of MS in $1.0 \mathrm{M} \mathrm{HCl}$ for various concentrations of the inhibitors: (a) BMQ, (b), FVQ and (c) STQ at $303 K$.
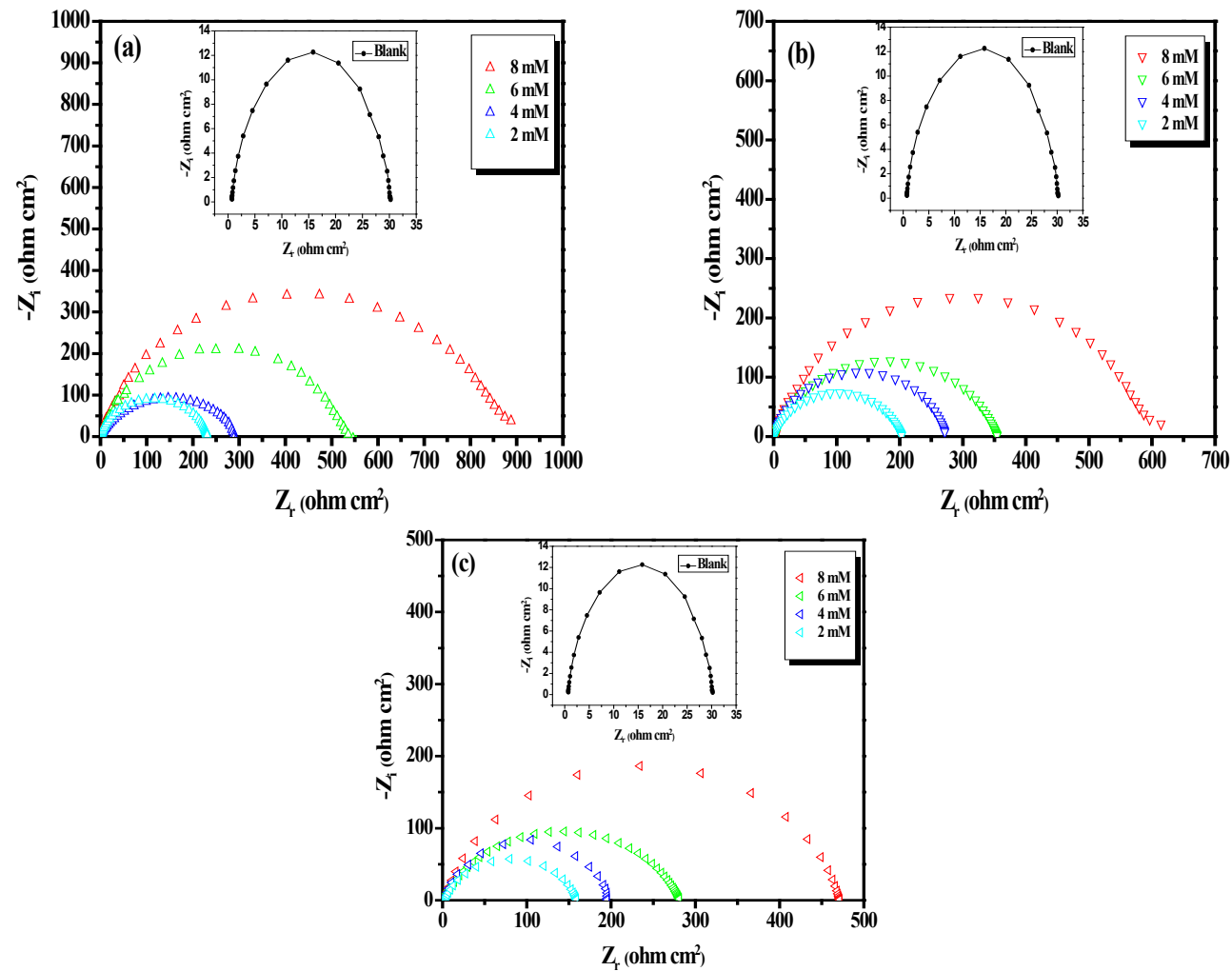

Figure 7: Nyquist curves for MS in $1.0 \mathrm{M} \mathrm{HCl}$ for selected concentrations of the inhibitors: (a) BMQ, (b) FVQ, and (c) STQ at 303K. 
Citation: Lgaz H, Salghi R, Jodeh S, Ramli Y, Larouj M, et al (2016) Understanding the Adsorption of Quinoxaline Derivatives as Corrosion Inhibitors for Mild Steel in Acidic Medium: Experimental, Theoretical and Molecular Dynamic Simulation Studies. J Steel Struct Constr 2: 111. doi:10.4172/2472-0437.1000111

Page 8 of 17

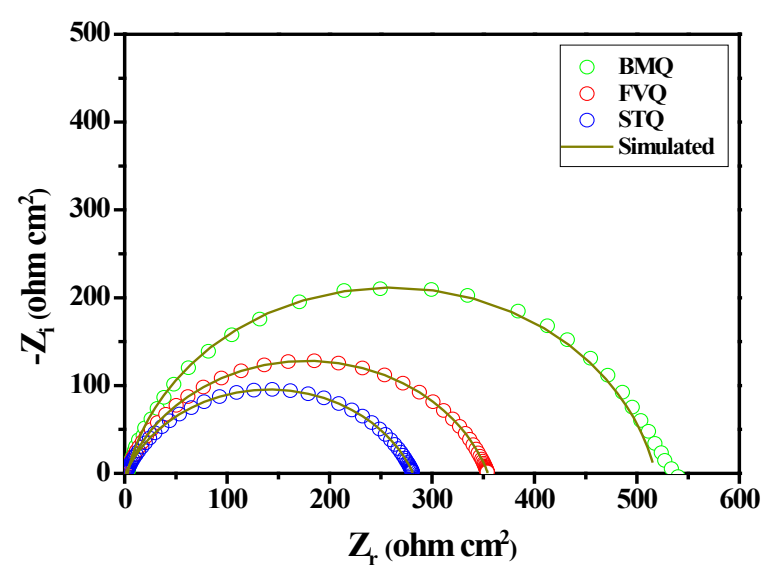

Figure 8: EIS Nyquist plots for carbon steel in $1.0 \mathrm{M} \mathrm{HCl}$ with $6 \mathrm{mM}$ of inhibitors interface: dotted lines experimental data; dashed line calculated.

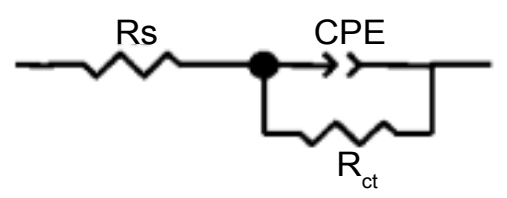

Figure 9: Equivalent electrical circuit corresponding to the corrosion process on the MS in hydrochloric acid.

$$
Z_{C P E}=\frac{1}{Q(\mathrm{j} \omega)^{n}}
$$

Where $\mathrm{Q}$ is the CPE constant (in $\Omega^{-1} \mathrm{~S}^{\mathrm{n}} \mathrm{cm}^{-2}$ ), $\omega$ is the angular frequency (in $\left.\operatorname{rad~s}^{-1}\right), j^{2}=-1$ is the imaginary number and $n$ is a $\mathrm{CPE}$ exponent which can be used as a gauge for the heterogeneity or roughness of the surface [63]. The electrochemical parameters derived from the fitting of impedance spectra are collected in Table 5. The IE\% was calculated by the Eq. (12):

$$
\eta_{E I S}(\%)=\left(\frac{\mathrm{R}_{c t}-\mathrm{R}_{c t}^{\circ}}{R_{c t}}\right) \times 100
$$

Where: $\mathrm{R}^{\circ}{ }_{\mathrm{ct}}$ and $\mathrm{R}_{\mathrm{ct}}$ are the charge transfer resistances without and with various concentrations of inhibitors respectively. According to the values of $\mathrm{R}_{\mathrm{ct}}$ displayed in Table 5 , the $\mathrm{R}_{\mathrm{ct}}$ value increase considerably with rising in inhibitors concentration (from 231.1 to $847.1 \Omega$ for BMQ) resulting in a slower corrosion of steel due to the adsorption of quinoxaline derivatives on metal surface [64,65]. Regarding, the double layer capacitances, $C_{\mathrm{dl}}$ is associated with a CPE by the following Eq.(13) [66]:

$$
C_{d l}=\left(Q \cdot R_{c t}^{1-n}\right)^{1 / n}
$$

The $\mathrm{C}_{\mathrm{dl}}$ values were decreased, so that the $\mathrm{C}_{\mathrm{dl}}$ values reached $15.09 \mu \mathrm{Fcm}^{-2}$ for BMQ, $18.48 \mu \mathrm{F} \mathrm{cm} \mathrm{cm}^{-2}$ for FVQ and $21.07 \mu \mathrm{F} \mathrm{cm} \mathrm{cm}^{-2}$ for STQ considering $85.89 \mu \mathrm{F} \mathrm{cm} \mathrm{cm}^{-2}$ for the uninhibited solution. On the other side, the values of the proportional factor $\mathrm{Q}$ of $\mathrm{CPE}$ increase when decreasing the concentration of the quinoxaline derivatives. These results are probably correlated with the adsorption of the three inhibitors on steel surface [66,67]. Accordingly, the values of $\mathrm{n}$ lies between 0.89 and 0.92 for inhibited solutions, the addition of quinoxaline derivatives increased $n$ values, indicating the increase in in-homogeneity of the MS surface, due to the adsorption of the our inhibitors [68,69].
The inhibition efficiency values in the absence and presence of BMQ, FVQ and STQ yielded $96.53 \%, 94.98 \%$ and $93.73 \%$ in the highest concentrations, respectively with the following order: BMQ > FVQ $>$ STQ. This order can be explained by the presence of a phenyl and $\left(-\mathrm{OCH}_{3}\right)$ in $\mathrm{BMQ}$, which raised their reactivity.

\section{SEM analysis}

SEM photomicrographs of the surface of MS were immersed for $6 \mathrm{~h}$ in a corrosive medium with and without $8 \mathrm{mM}$ of STQ, BMQ and FVQ. Results are displayed in Figures 10a-10e. In acidic environment, obvious dissolution can be observed without the presence of any inhibitors. In presence of BMQ, FVQ and STQ, it can be seen (Figures 10a-10c) that the surface of the MS was improved, smooth, and that less pits and less damage was observed, This demonstrates the formation of insoluble film, resulting from the adsorption of BMQ, FVQ and STQ on the MS surface. These observations support the high inhibition performance of the quinoxaline derivatives.

\section{Quantum chemical calculations}

Global molecular reactivity: We attempted to interpret the main factors responsible for the reactivity of the investigated quinoxaline derivatives and to analyse the capability of our molecules to donate and accept electrons to/and from the MS surface. The optimized structures of the quinoxaline derivatives molecules were calculated and presented in Figure 11. The QCPs such as $\mathrm{E}_{\mathrm{HOMO}}, \mathrm{E}_{\mathrm{LUMO}}, \Delta \mathrm{E}=\left(\mathrm{E}_{\mathrm{LUMO}}-\mathrm{E}_{\mathrm{HOMO}}\right)$, total energy (TE), softness $(\sigma)$, the fraction of electrons transferred $(\Delta \mathrm{N})$ and dipole moment $(\mu)$ were collected in Table 6 . The IE\% of BMQ, FVQ and STQ according to our experimental studies is:

\section{BMQ $>$ FVQ $>$ STQ}

In Figure 11, The HOMO and LUMO orbitals are distributed over the entire quinoxaline molecules, resulting in the highest interaction of quinoxaline derivatives studied on the MS surface. This observation also suggests that the heteroatoms and the cycle rings containing $\pi$-bonds are the probable reactive sites for adsorption of inhibitors on the metal surface. Normally, $\mathrm{E}_{\text {номо }}$ is often indicated the ability of a molecule to donate electrons; this ability becomes more considerable with a high value of $\mathrm{E}_{\text {номо }}$. While, the lowering of $\mathrm{E}_{\mathrm{LUMO}}$ is often associated with the capability of an inhibitor to accept electrons [70,71]. The $\Delta \mathrm{E}=\left(\mathrm{E}_{\mathrm{LUMO}}\right.$ $\mathrm{E}_{\text {номо }}$ ) was reported as a main chemical reactivity factor of an inhibitor from theoretical point of view [71]. According to these literature findings

\begin{tabular}{|c|c|c|c|c|c|c|c|}
\hline Inhibitor & $\begin{array}{c}\text { Conc } \\
\text { (M) }\end{array}$ & $\begin{array}{c}R_{\mathrm{ct}} \\
\left(\Omega \mathrm{cm}^{2}\right)\end{array}$ & $\mathrm{n}$ & $\begin{array}{c}Q \times 10^{-4} \\
\left(\mathrm{~s}^{\mathrm{n}}\right. \\
\left.\Omega^{-1} \mathrm{~cm}^{-2}\right)\end{array}$ & $\begin{array}{c}\mathrm{C}_{\mathrm{dl}} \\
\left(\mu \mathrm{F} \mathrm{\textrm {cm } ^ { - 2 }}\right)\end{array}$ & $\begin{array}{c}\eta_{z} \\
(\%)\end{array}$ & $\theta$ \\
\hline Blank & 1.0 & 29.35 & 0.88 & 1.7610 & 85.89 & - & - \\
\hline \multirow{4}{*}{$\mathrm{BMQ}$} & 8 & 847.1 & 0.92 & 0.2139 & 15.09 & 96.53 & 0.9653 \\
\hline & 6 & 515.2 & 0.89 & 0.2870 & 17.05 & 94.30 & 0.9430 \\
\hline & 4 & 301.3 & 0.91 & 0.3354 & 21.29 & 90.25 & 0.9025 \\
\hline & 2 & 231.1 & 0.93 & 0.4112 & 28.96 & 87.29 & 0.8729 \\
\hline \multirow{4}{*}{ FVQ } & 8 & 585.2 & 0.92 & 0.2655 & 18.48 & 94.98 & 0.9498 \\
\hline & 6 & 353.4 & 0.92 & 0.2889 & 19.39 & 91.69 & 0.9169 \\
\hline & 4 & 273.3 & 0.93 & 0.3702 & 26.20 & 89.26 & 0.8926 \\
\hline & 2 & 203.3 & 0.91 & 0.4812 & 30.45 & 85.56 & 0.8556 \\
\hline \multirow{4}{*}{ STQ } & 8 & 468.8 & 0.93 & 0.2911 & 21.07 & 93.73 & 0.9373 \\
\hline & 6 & 280.7 & 0.91 & 0.3546 & 22.48 & 89.54 & 0.8954 \\
\hline & 4 & 192.3 & 0.92 & 0.4132 & 27.14 & 84.73 & 0.8473 \\
\hline & 2 & 156.2 & 0.91 & 0.5170 & 32.10 & 81.20 & 0.8120 \\
\hline
\end{tabular}
and the results from Table 6, it can be observed that our compounds have higher interactions with the steel surface. The reactivity of BMQ, FVQ and

Table 5: AC-impedance parameters for corrosion of MS for selected concentrations of the inhibitors in $1.0 \mathrm{M} \mathrm{HCl}$ at $303 \mathrm{~K}$. 
Citation: Lgaz H, Salghi R, Jodeh S, Ramli Y, Larouj M, et al (2016) Understanding the Adsorption of Quinoxaline Derivatives as Corrosion Inhibitors for Mild Steel in Acidic Medium: Experimental, Theoretical and Molecular Dynamic Simulation Studies. J Steel Struct Constr 2: 111. doi:10.4172/2472-0437.1000111

Page 9 of 17

\begin{tabular}{|c|c|c|c|c|c|c|c|c|c|c|}
\hline Molecule & $\begin{array}{c}E_{\text {номо }} \\
(\mathrm{eV})\end{array}$ & $\begin{array}{c}E_{\text {Lumo }} \\
(\mathrm{eVV})\end{array}$ & $\Delta E(e V)$ & $\mu(\mathrm{eV})$ & $\mathrm{TE}(\mathrm{eV})$ & $\eta(e V)$ & $\sigma\left(\mathrm{eV}^{-1}\right)$ & $x(e V)$ & $\Delta \mathrm{N}$ & IE (\%) \\
\hline BMQ & -3.7557 & -1.0245 & 2.7312 & 2.3105 & -1111.9 & 1.3656 & 0.7323 & 2.3901 & 0.6114 & 96.53 \\
\hline FVQ & -5.4151 & -2.2308 & 3.1843 & 2.1136 & -799.5 & 1.5922 & 0.6281 & 3.8229 & 0.0744 & 94.98 \\
\hline STQ & -5.6441 & -2.2650 & 3.3791 & 2.2391 & -801.6 & 1.6895 & 0.5918 & 3.9546 & 0.0312 & 93.73 \\
\hline
\end{tabular}

Table 6: Calculated quantum chemical parameters of the inhibitors molecules.
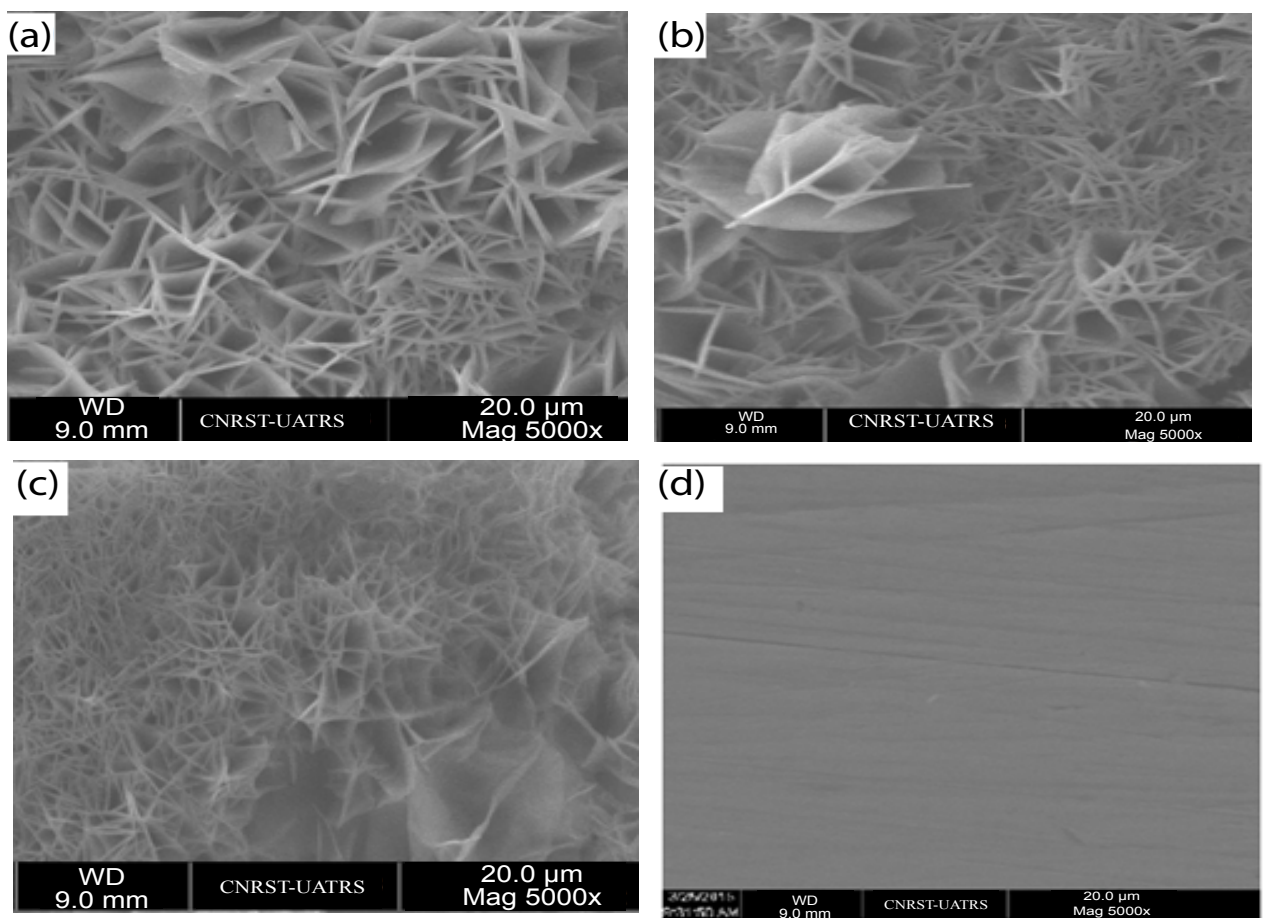

(d)

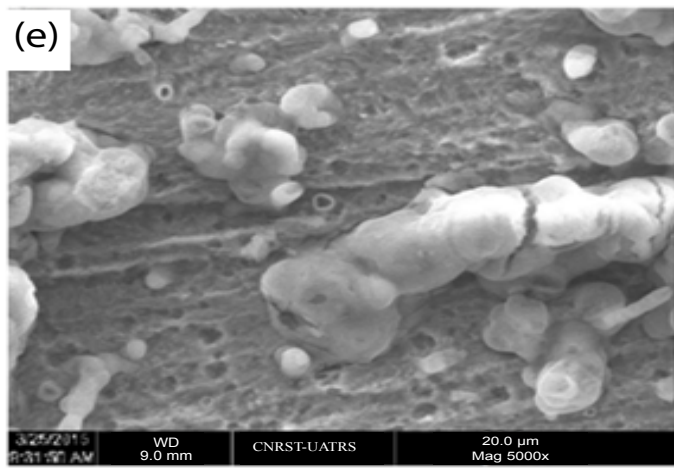

Figure 10: SEM photographs of MS: $1 \mathrm{M} \mathrm{HCl}$ with $8 \mathrm{mM}$ of (a) BMQ, (b) FVQ and (c) STQ. (d) Polished and (e) immersed in $1 \mathrm{M} \mathrm{HCl}$.

STQ can be classified by the following order:

\section{BMQ $>$ FVQ $>$ STQ}

Recently, Olasunkanmi et al. [14] employed four quinoxaline derivatives, noted Me-4-PQPB, Mt-4-PQPB, Mt-3-PQPB and Oxo1,3-PQPB to study the corrosion inhibition of MS in hydrochloric acid medium, the authors reported that the $I E \%$ values at optimum concentration are $80.42 \%, 72.01 \%, 69.66 \%$ and $68.41 \%$ respectively. While, in the theoretical calculations the $\Delta \mathrm{E}$ values are found to be $3.55,3.93,3.93$ and 3.67 , these results further support the inhibitive performance of our compounds.

The absolute electronegativity $(\chi)$ and global hardness $(\eta)$ of the inhibitors molecule are approximated as follows [72,73]:

$$
\begin{gathered}
\chi=\frac{I+A}{2} \\
\eta=\frac{I-A}{2}
\end{gathered}
$$

Where: $\mathrm{I}=-\mathrm{E}_{\text {Hомо }}$ and $\mathrm{A}=-\mathrm{E}_{\mathrm{LUMO}}$

Thus the fraction of electrons transferred from the inhibitor to metallic surface, $\Delta \mathrm{N}$, is given by [74]:

$$
\Delta N=\frac{\chi_{F e}-\chi_{i n h}}{2\left(\eta_{F e}+\eta_{i n h}\right)}
$$


Citation: Lgaz H, Salghi R, Jodeh S, Ramli Y, Larouj M, et al (2016) Understanding the Adsorption of Quinoxaline Derivatives as Corrosion Inhibitors for Mild Steel in Acidic Medium: Experimental, Theoretical and Molecular Dynamic Simulation Studies. J Steel Struct Constr 2: 111. doi:10.4172/2472-0437.1000111

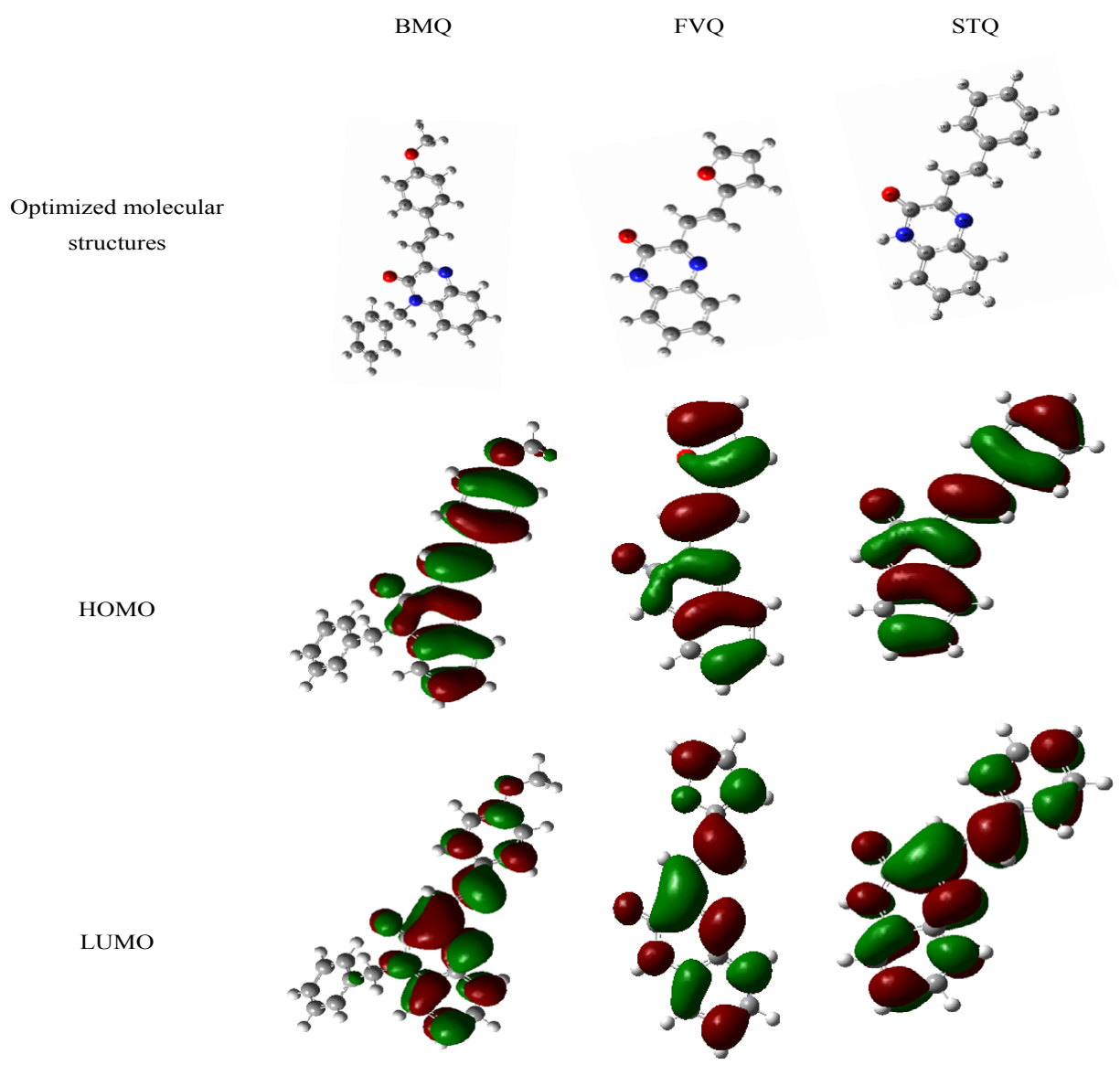

Figure 11: Frontier molecule orbital density distributions of the synthesized inhibitors.

- The theoretical values of $\chi_{\mathrm{Fe}}\left(4.06 \mathrm{eV} \mathrm{mol}^{-1}\right)$ and of $\eta_{\mathrm{Fe}}\left(0 \mathrm{eV} \mathrm{mol}^{-1}\right)$ are used to calculate $\Delta N[75,76]$. The results from Table 6, show that the order of electron transfer is such that BMQ $>$ FVQ $>$ STQ which also confirms that BMQ has the highest tendency to donate electrons and therefore the highest tendency to bind onto the metal surface [76,77].

The hard-soft-acid-base (HSAB) theory introduced by Pearson [78] can be used in correlation with the FMO theory to understanding the tendencies of the inhibitors to bonding towards the MS atoms [79]. According to HSAB theory, hard acids prefer to co-ordinate to hard bases to give ionic complexes and soft acids prefer binding to soft bases to give covalent complexes. On the other hand, metal atoms are definite as soft acids. Hard molecules have a high value of $\Delta \mathrm{E}_{\text {номо- }}$ LUмO. In contrast, soft molecules have a small $\Delta \mathrm{E}_{\text {Hомо-Lumo }}$ [80]. Thus soft base compounds are the most capable to bind with metal atoms. So, the BMQ compound which has the lowest $\Delta \mathrm{E}_{\text {Hомо-Lumo }}$ and the highest softness has mostly been confirmed by calculating the softness, $\sigma$, to measures the reactivity of a molecule: $\sigma=1 / \eta$, (Table 6). It was observed that BMQ compounds have the highest $\sigma$ value and the order at which softness increases, so that the reactivity will be:

\section{BMQ $>$ FVQ $>$ STQ}

Figure 12 shows the relationship between the FMO of quinoxaline compounds studied and their energy gap $\triangle \mathrm{Eg}$. BMQ, FVQ and STQ have low energy gap, which facilitate their adsorption. The order of the reactivity of tested molecules is clearly observed from this figure by considering a small difference between the energy of HOMO and LUMO $[81,82]$.

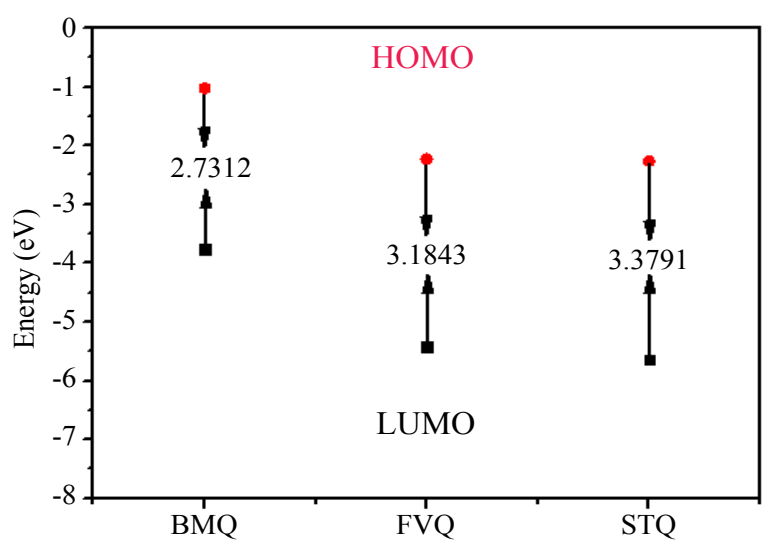

Figure 12: Correlation diagram, molecular orbital borders and the gap energy derivatives quinoxaline compounds.

Actives sites: To investigate reactive sites in the tested inhibitors, molecular electrostatic potential (MESP) provides a visual method to understand the region of the electrophilic attack, nucleophilic attack and the electrostatic potential zero regions [83]. The total electron density surface mapped with molecular electrostatic potential (MEP) and contour representation of electrostatic potential of BMQ, FVQ and STQ are collected in Figures 13a-13b, respectively. In these maps, different values of the MESP were demonstrated with the help of different colors, which are red, yellow, green, light blue and blue. The 
Citation: Lgaz H, Salghi R, Jodeh S, Ramli Y, Larouj M, et al (2016) Understanding the Adsorption of Quinoxaline Derivatives as Corrosion Inhibitors for Mild Steel in Acidic Medium: Experimental, Theoretical and Molecular Dynamic Simulation Studies. J Steel Struct Constr 2: 111. doi:10.4172/2472-0437.1000111

Page 11 of 17

red and yellow colors suitable for the negative parts of the MEP are linked to electrophilic reactivity, blue colors suitable for the positive parts to the nucleophilic reactivity and the green color represents the ESP zero region. In Figures 13a-13c, the red and yellow sites are mainly observed over the benzene ring, the heteroatoms (N13, N14, and Oxygen atoms) and the conjugated double bonds, the blue and light blue sites are mainly localized around the second atom of nitrogen and benzene ring. The green regions stand for the zero electrostatic potential.

These remarks confirmed by the Mulliken charges of the inhibitor atoms as can be seen in Figure 13c [84]. As noticed that the MS acting as an electrophilic, and the nucleophilic centers are heteroatoms with free electron pairs and $\pi$-systems in the conjugated double bonds. The inhibitors can promote formation of a chelate on the MS surface by transferring electrons from tested molecules to Fe-atoms (d-orbital) and forming a coordinate covalent bond through the adsorption process [85].

In order to analyze the active sites of BMQ, FVQ and STQ, Fukui indices was used to measure the local reactivity of the inhibitors molecules and indicate their chemical reactivity for nucleophilic and electrophilic nature. The condensed Fukui functions can be computed unambiguously using a scheme of finite difference approximations such as [86]:

$$
\begin{aligned}
& f_{k}^{+}=P_{k}(N+1)-P_{k}(N) \\
& f_{k}^{+}=P_{k}(N)-P_{k}(N-1)
\end{aligned}
$$

where $P_{k}(N+1), P_{k}(N), P_{k}(N-1)$ represent charge values of atom $\mathrm{k}$ for anion, neutral, and cation, respectively.

Generally, the high value of $f_{k}^{+}$is the preferred site for nucleophilic attack, while the sites with a high value of $f_{k}^{-}$are preferred for electrophilic attack, The Fukui indices for BMQ, FVQ and STQ are present in Tables 7-9. In BMQ atoms C1(0.09169), C5(0.08025), N14(0.18102), C32(0.09582), in FVQ atoms C1(0.08292), C15(0.10027), C22(0.09368), C26(0.10635) and in STQ atoms $\mathrm{C} 1(0.07165), \mathrm{C} 11(0.10305), \mathrm{N} 13(0.10207), \mathrm{C} 17(0.13096)$, presented the highest values of $f_{k}^{+}$regarding the most susceptible sites for nucleophilic attacks. On the other hand, in BMQ atoms C12(0.1312), N14(0.11428), N15(0.09401), C32(0.0813), in FVQ atoms C11(0.10201), N13(0.10542), C17(0.12482), C22(0.08514) and in STQ atoms $\mathrm{C} 1(0.07756), \mathrm{N} 13(0.06573), \mathrm{C} 15(0.09977), \mathrm{C} 26(0.06255)$ are the preferable sites for electrophilic attacks and consequently donating charges to the MS surface, as they presented the highest values of $f_{k}^{-}$. Based on these findings, the distribution of the active sites is quite different. This implies the highest capacity of adsorption of BMQ, FVQ and (a) BMQ

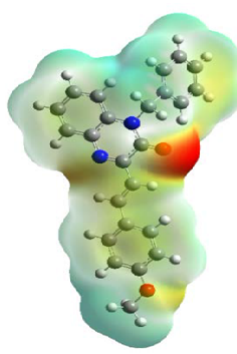

(b)
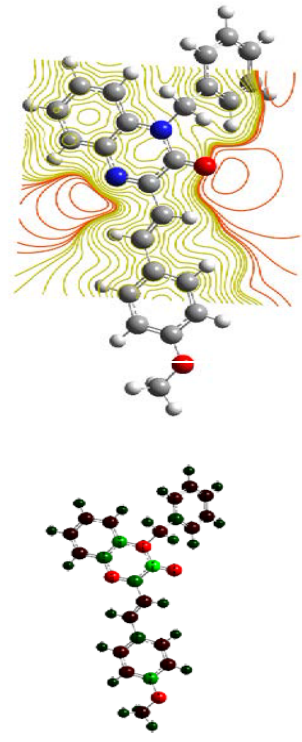

FVQ

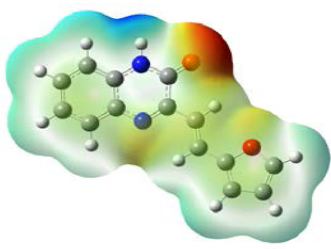

Electron Density
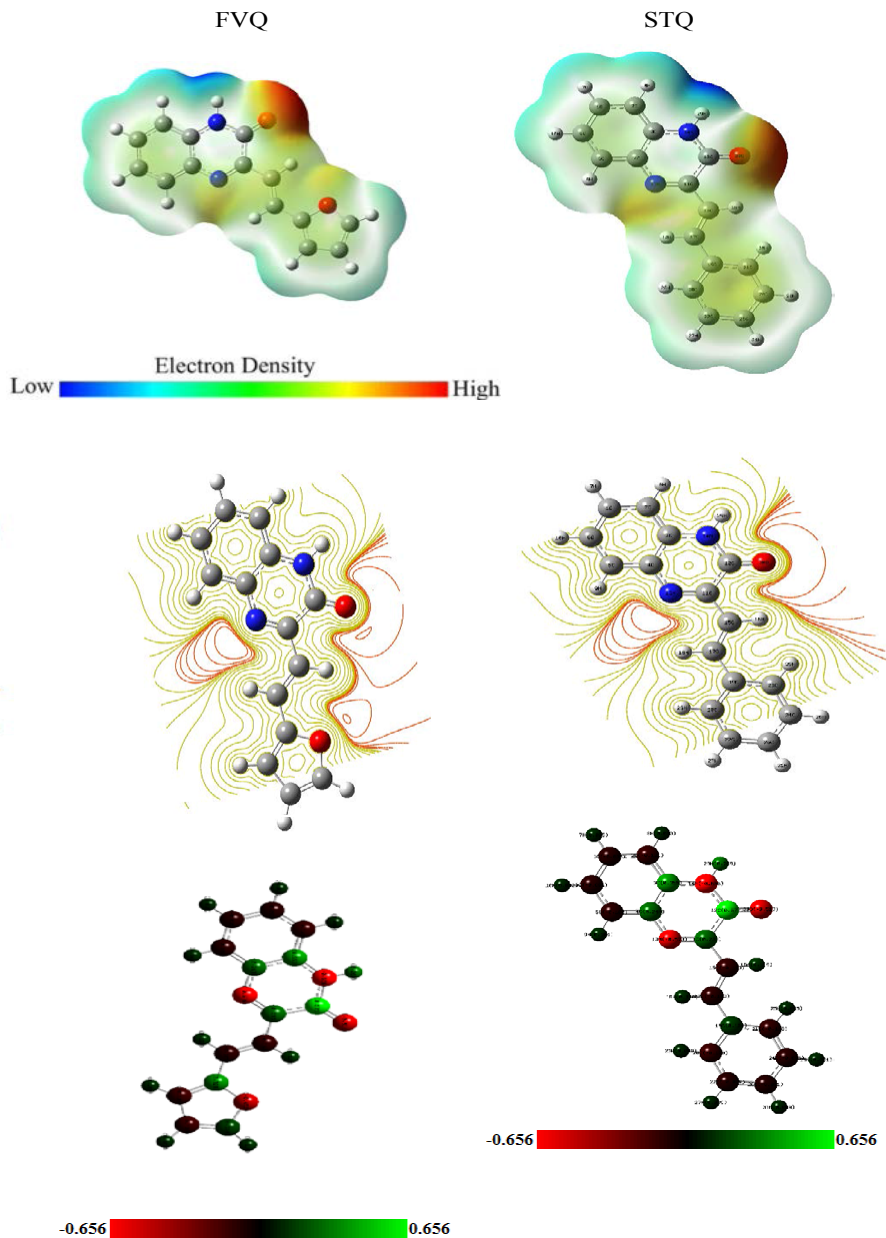

Figure 13: Quantum chemical results of inhibitors molecules: (a) total electron density surface mapped with electrostatic potential (b) contour representation of electrostatic potential (c) optimized structures with Mulliken charges values. 
Citation: Lgaz H, Salghi R, Jodeh S, Ramli Y, Larouj M, et al (2016) Understanding the Adsorption of Quinoxaline Derivatives as Corrosion Inhibitors for Mild Steel in Acidic Medium: Experimental, Theoretical and Molecular Dynamic Simulation Studies. J Steel Struct Constr 2: 111. doi:10.4172/2472-0437.1000111

Page 12 of 17

\begin{tabular}{|c|c|c|c|c|c|}
\hline Atom & $P_{k}(N)$ & $P_{k}(N-1)$ & $P_{k}(N+1)$ & $f_{k}^{+}$ & $f_{k}^{-}$ \\
\hline C1 & 6.23558 & 6.18033 & 6.32727 & 0.09169 & 0.05525 \\
\hline $\mathrm{C} 2$ & 6.2817 & 6.25357 & 6.30889 & 0.02719 & 0.02813 \\
\hline C3 & 5.85758 & 5.84064 & 5.89793 & 0.04035 & 0.01694 \\
\hline C4 & 5.85067 & 5.83482 & 5.80619 & -0.04448 & 0.01585 \\
\hline C5 & 6.23144 & 6.19993 & 6.31169 & 0.08025 & 0.03151 \\
\hline C6 & 6.2448 & 6.20515 & 6.24764 & 0.00284 & 0.03965 \\
\hline $\mathrm{H} 7$ & 0.76081 & 0.73029 & 0.79493 & 0.03412 & 0.03052 \\
\hline $\mathrm{H} 8$ & 0.7586 & 0.73349 & 0.78791 & 0.02931 & 0.02511 \\
\hline H9 & 0.75042 & 0.72527 & 0.77485 & 0.02443 & 0.02515 \\
\hline $\mathrm{H} 10$ & 0.75985 & 0.72935 & 0.79191 & 0.03206 & 0.0305 \\
\hline C11 & 5.87376 & 5.85386 & 5.87798 & 0.00422 & 0.0199 \\
\hline C12 & 6.04397 & 5.91277 & 6.0721 & 0.02813 & 0.1312 \\
\hline $\mathrm{H} 13$ & 0.76788 & 0.73284 & 0.79796 & 0.03008 & 0.03504 \\
\hline N14 & 7.48157 & 7.36729 & 7.66259 & 0.18102 & 0.11428 \\
\hline N15 & 7.36283 & 7.26882 & 7.40386 & 0.04103 & 0.09401 \\
\hline C16 & 6.26679 & 6.27745 & 6.25942 & -0.00737 & -0.01066 \\
\hline $\mathrm{H} 17$ & 0.74914 & 0.72348 & 0.76654 & 0.0174 & 0.02566 \\
\hline $\mathrm{H} 18$ & 0.74178 & 0.7262 & 0.7573 & 0.01552 & 0.01558 \\
\hline C19 & 6.06095 & 6.08532 & 6.04527 & -0.01568 & -0.02437 \\
\hline $\mathrm{C} 20$ & 6.23755 & 6.23348 & 6.23939 & 0.00184 & 0.00407 \\
\hline $\mathrm{C} 21$ & 6.22987 & 6.23789 & 6.21788 & -0.01199 & -0.00802 \\
\hline $\mathrm{C} 22$ & 6.22851 & 6.21531 & 6.23725 & 0.00874 & 0.0132 \\
\hline $\mathrm{H} 23$ & 0.76344 & 0.75466 & 0.76859 & 0.00515 & 0.00878 \\
\hline $\mathrm{C} 24$ & 6.22518 & 6.21622 & 6.23611 & 0.01093 & 0.00896 \\
\hline $\mathrm{H} 25$ & 0.75118 & 0.76433 & 0.74635 & -0.00483 & -0.01315 \\
\hline C26 & 6.23765 & 6.21798 & 6.25236 & 0.01471 & 0.01967 \\
\hline $\mathrm{H} 27$ & 0.75792 & 0.74163 & 0.77176 & 0.01384 & 0.01629 \\
\hline $\mathrm{H} 28$ & 0.75645 & 0.74423 & 0.76697 & 0.01052 & 0.01222 \\
\hline $\mathrm{H} 29$ & 0.75798 & 0.74189 & 0.77235 & 0.01437 & 0.01609 \\
\hline $\mathrm{C} 30$ & 6.24623 & 6.29467 & 6.2485 & 0.00227 & -0.04844 \\
\hline H31 & 0.78263 & 0.76577 & 0.8019 & 0.01927 & 0.01686 \\
\hline C32 & 6.19393 & 6.11263 & 6.28975 & 0.09582 & 0.0813 \\
\hline H33 & 0.74856 & 0.74406 & 0.75768 & 0.00912 & 0.0045 \\
\hline C34 & 6.09896 & 6.12032 & 6.07953 & -0.01943 & -0.02136 \\
\hline C35 & 6.1919 & 6.16487 & 6.22197 & 0.03007 & 0.02703 \\
\hline C36 & 6.19907 & 6.18323 & 6.2274 & 0.02833 & 0.01584 \\
\hline C37 & 6.32432 & 6.31734 & 6.33328 & 0.00896 & 0.00698 \\
\hline H38 & 0.76043 & 0.75246 & 0.77066 & 0.01023 & 0.00797 \\
\hline C39 & 6.27355 & 6.26308 & 6.28249 & 0.00894 & 0.01047 \\
\hline $\mathrm{H} 40$ & 0.76582 & 0.76117 & 0.77356 & 0.00774 & 0.00465 \\
\hline C41 & 5.67758 & 5.63876 & 5.72521 & 0.04763 & 0.03882 \\
\hline $\mathrm{H} 42$ & 0.75837 & 0.74273 & 0.77762 & 0.01925 & 0.01564 \\
\hline $\mathrm{H} 43$ & 0.751 & 0.73485 & 0.77112 & 0.02012 & 0.01615 \\
\hline O44 & 8.51805 & 8.495 & 8.53246 & 0.01441 & 0.02305 \\
\hline C45 & 6.32793 & 6.33532 & 6.32191 & -0.00602 & -0.00739 \\
\hline $\mathrm{H} 46$ & 0.79377 & 0.78564 & 0.80031 & 0.00654 & 0.00813 \\
\hline $\mathrm{H} 47$ & 0.76826 & 0.7541 & 0.78299 & 0.01473 & 0.01416 \\
\hline $\mathrm{H} 48$ & 0.79378 & 0.7855 & 0.80043 & 0.00665 & 0.00828 \\
\hline
\end{tabular}

Table 7: Natural population and Fukui functions of BMQ, calculated at B3LYP/6$31 \mathrm{G}(\mathrm{d}, \mathrm{p})$ in gas phase.

STQ on the MS surface; these results are in good correlation with the experimental IE\%.

\section{Monte Carlo (Molecular dynamic) simulation}

Molecular dynamics (MD) simulation provides considerable information about the physical movements of atoms and molecules, which gives a view of the motion of the atoms after interaction at a certain time. Figure 14 represents the top and side views of the most

suitable configuration for adsorption of quinoxaline derivatives on Fe $\left(\begin{array}{lll}1 & 1 & 0\end{array}\right)$ substrates obtained by Monte Carlo simulation. The total energy, average total energy, van der Waals energy, electrostatic energy and intramolecular energy for $\mathbf{B M Q} / \mathrm{Fe}\left(\begin{array}{lll}1 & 1 & 0\end{array}\right)$ surface were calculated by optimizing the whole system; the curves are presented in Figure 15. The outputs and descriptors calculated by the Monte Carlo simulation are presented in Table 10. It is clearly observed from Figure 14 that the three quinoxaline derivatives adsorbed very nearly and in parallel to the $\mathrm{Fe}\left(\begin{array}{lll}1 & 1 & 0\end{array}\right)$ surface in so as to maximize surface contact. This adsorption process occurs mainly through the formation of the insoluble film on the $\mathrm{Fe}\left(\begin{array}{lll}1 & 1 & 0\end{array}\right)$ surface. It is generally noted that the adsorption process is the primary mechanism of corrosion inhibitor interaction with the MS. According to Table 10, the adsorption energies of BMQ, FVQ and STQ on the Fe $\left(\begin{array}{lll}1 & 1 & 0\end{array}\right)$ surface increased in the order BMQ > FVQ > STQ. The high negative values of adsorption energy of quinoxaline derivatives resulted in the strong interactions between mild steel and inhibitors molecules $[87,88]$. Which is in good accordance with the order of the $I E \%$ obtained by experimental and theoretical studies.

\section{Radial distribution function (pair correlation function)}

Pair correlation function was done in order to characterize the bond length and understand the interactions of the liquid and solid materials. The pair correlation function analysis can be calculated from the trajectory output of Monte Carlo simulation, and the basic information of molecule-molecule interaction can be obtained by the calculation of bonding length. Approximately, the bond lengths of van der Waals interaction are around $5 \AA \sim 10 \AA$, while, bond lengths around $2 \AA \sim 3 \AA$ exist for metal complexation, and $\mathrm{H}$ bond lengths

\begin{tabular}{|c|c|c|c|c|c|}
\hline Atom & $P_{k}(N)$ & $P_{k}(N-1)$ & $P_{k}(N+1)$ & $f_{k}^{+}$ & $f_{k}^{-}$ \\
\hline C1 & 6.21617 & 6.13325 & 6.28993 & 0.08292 & 0.07376 \\
\hline $\mathrm{C} 2$ & 6.2738 & 6.27643 & 6.29536 & -0.00263 & 0.02156 \\
\hline $\mathrm{C} 3$ & 5.83905 & 5.79178 & 5.86767 & 0.04727 & 0.02862 \\
\hline C4 & 5.88898 & 5.85603 & 5.8695 & 0.03295 & -0.01948 \\
\hline C5 & 6.2058 & 6.17683 & 6.259 & 0.02897 & 0.0532 \\
\hline C6 & 6.25865 & 6.23652 & 6.27016 & 0.02213 & 0.01151 \\
\hline $\mathrm{H} 7$ & 0.75504 & 0.7266 & 0.78621 & 0.02844 & 0.03117 \\
\hline $\mathrm{H} 8$ & 0.75914 & 0.73335 & 0.78638 & 0.02579 & 0.02724 \\
\hline $\mathrm{H} 9$ & 0.74663 & 0.72829 & 0.76772 & 0.01834 & 0.02109 \\
\hline $\mathrm{H} 10$ & 0.75481 & 0.72733 & 0.78374 & 0.02748 & 0.02893 \\
\hline C11 & 5.84971 & 5.87795 & 5.95172 & -0.02824 & 0.10201 \\
\hline C12 & 5.36712 & 5.37374 & 5.3666 & -0.00662 & -0.00052 \\
\hline N13 & 7.42909 & 7.36143 & 7.53451 & 0.06766 & 0.10542 \\
\hline N14 & 7.5928 & 7.56458 & 7.62277 & 0.02822 & 0.02997 \\
\hline C15 & 6.26023 & 6.15996 & 6.25541 & 0.10027 & -0.00482 \\
\hline H16 & 0.73282 & 0.71214 & 0.75768 & 0.02068 & 0.02486 \\
\hline C17 & 6.21247 & 6.16189 & 6.33729 & 0.05058 & 0.12482 \\
\hline $\mathrm{H} 18$ & 0.74159 & 0.71956 & 0.76004 & 0.02203 & 0.01845 \\
\hline $\mathrm{H} 19$ & 0.56136 & 0.53755 & 0.58985 & 0.02381 & 0.02849 \\
\hline $\mathrm{O} 20$ & 8.61062 & 8.548 & 8.66952 & 0.06262 & 0.0589 \\
\hline $\mathrm{C} 21$ & 5.73382 & 5.70826 & 5.70547 & 0.02556 & -0.02835 \\
\hline $\mathrm{C} 22$ & 6.28375 & 6.19007 & 6.36889 & 0.09368 & 0.08514 \\
\hline $\mathrm{O} 23$ & 8.44743 & 8.44619 & 8.46659 & 0.00124 & 0.01916 \\
\hline $\mathrm{C} 24$ & 6.33764 & 6.31054 & 6.34671 & 0.0271 & 0.00907 \\
\hline $\mathrm{H} 25$ & 0.74659 & 0.71959 & 0.76898 & 0.027 & 0.02239 \\
\hline $\mathrm{C} 26$ & 5.88059 & 5.77424 & 5.95216 & 0.10635 & 0.07157 \\
\hline $\mathrm{H} 27$ & 0.74606 & 0.71232 & 0.7744 & 0.03374 & 0.02834 \\
\hline $\mathrm{H} 28$ & 0.76826 & 0.73558 & 0.79574 & 0.03268 & 0.02748 \\
\hline
\end{tabular}

Table 8: Natural population and Fukui functions of FVQ calculated at B3LYP/6-31G $(d, p)$ in gas phase. 
Citation: Lgaz H, Salghi R, Jodeh S, Ramli Y, Larouj M, et al (2016) Understanding the Adsorption of Quinoxaline Derivatives as Corrosion Inhibitors for Mild Steel in Acidic Medium: Experimental, Theoretical and Molecular Dynamic Simulation Studies. J Steel Struct Constr 2: 111. doi:10.4172/2472-0437.1000111

Page 13 of 17
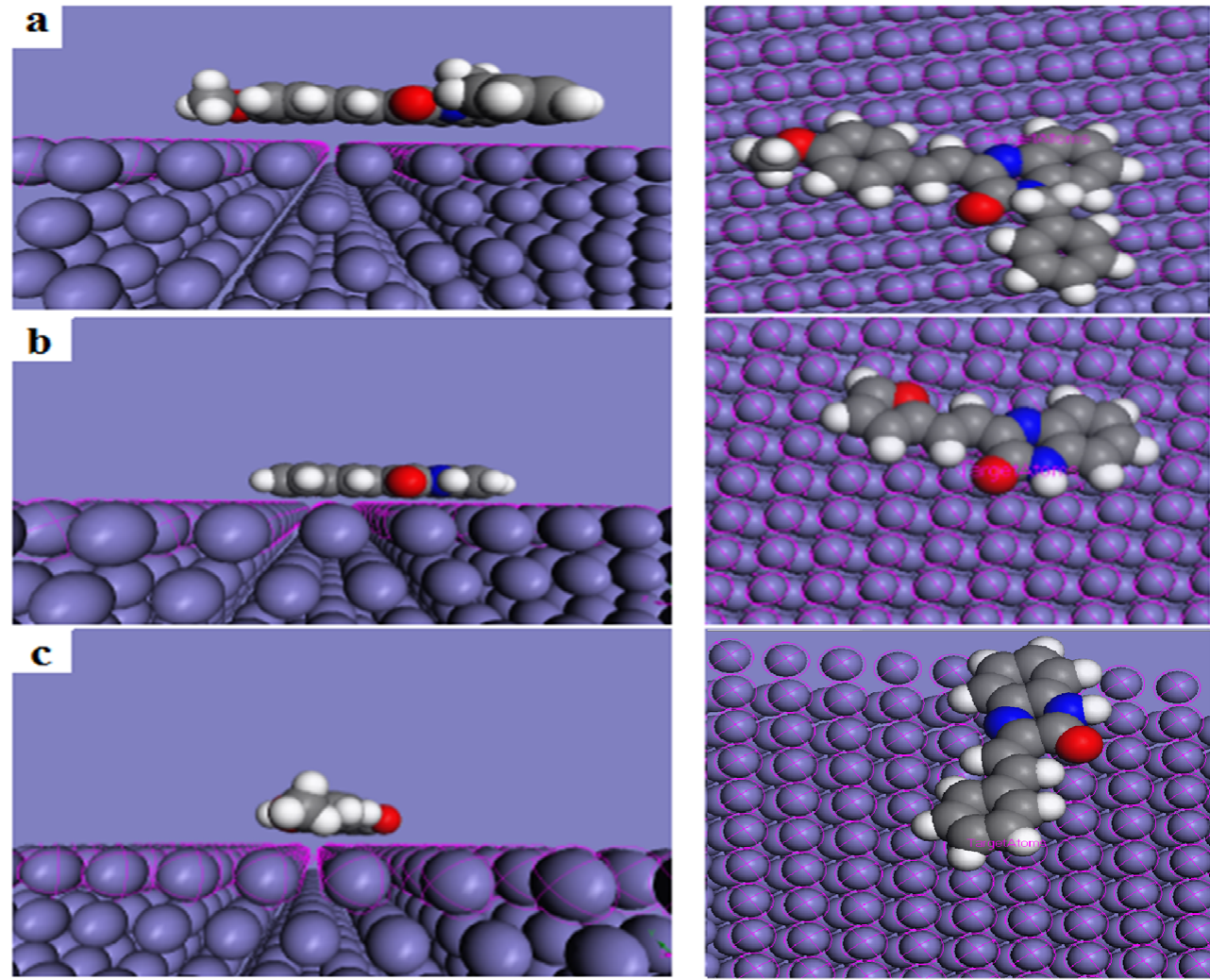

Figure 14: The side and top views of the most stable low energy conFigureuration for the adsorption of the inhibitors on Fe (1 10 ) surface obtained through the Monte Carlo simulation.(a) BMQ, (b) FVQ, and (c) STQ
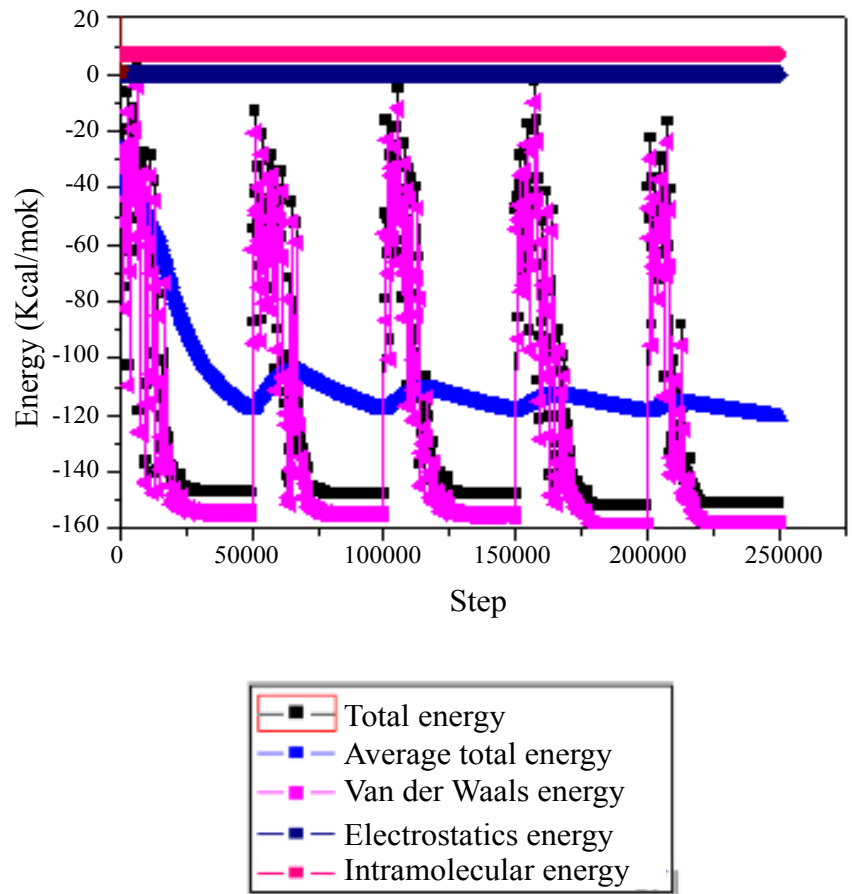

Figure 15: A typical energy profile for the adsorption progress of BMQ on Fe (110) surface using the Monte Carlo sampling procedure. exist at around $2 \AA \sim 3.5 \AA$. The pair correlation function, g(r), of C, N, and $\mathrm{O}$ of quinoxaline derivatives atoms and surface atoms was depicted in Figure 16. Generally, the chemical bonds can be formatted in correlation with the peak within $3.5 \AA$, while the Van der Waals force or Coulomb force interactions are correlated with the peak outside of 3.5 $\AA$. We will consider the distribution of heteroatoms according to their importance on the adsorption process of chemical compounds on the metal surface, while, the carbons atoms reactivity can be obtained from $\pi$-system. For STQ, the highest peaks of the pair correlation function curve of $\mathrm{O}, \mathrm{C}$ and $\mathrm{N}$ atoms appear at $3.43 \AA$, and the interactive force of these atoms on the Fe ( $\left(\begin{array}{lll}1 & 1 & 0\end{array}\right)$ surface follow the same trend. For BMQ, the highest peaks of the pair correlation function curve of $\mathrm{C}, \mathrm{N}$, and $\mathrm{O}$ atoms appear at $2.55 \AA, 2.85 \AA$, and $2.55 \AA$, respectively, and the interactive force of these atoms during the interaction with the $\mathrm{Fe}(11$ 0 ) surface follow the order of $F(O)=F(C)>F(N)$. For FVQ, the highest peaks of the pair correlation function curve of $\mathrm{C}, \mathrm{N}$, and $\mathrm{O}$ atoms appear at $2.85 \AA, 3.15 \AA$, and $2.85 \AA$, respectively, and the interactive force of $\mathrm{C}, \mathrm{N}$, and $\mathrm{O}$ atoms occur during interaction with the $\mathrm{Fe}\left(\begin{array}{ll}1 & 1\end{array}\right.$ 0 ) surface following the order of $\mathrm{F}(\mathrm{C})=\mathrm{F}(\mathrm{O})>\mathrm{F}(\mathrm{N})$. Overall, the pair correlation function curves of $\mathrm{C}, \mathrm{N}$, and $\mathrm{O}$ of quinoxaline derivatives and the $\mathrm{Fe}\left(\begin{array}{lll}1 & 1 & 0\end{array}\right)$ surface show that the highest peak of all interaction appeared within $3.5 \AA$. This indicates that chemical bonds can be formed between active centers of investigated compounds and Fe (1 11 0 ) atoms, confirming the high inhibition efficiency of tested inhibitors.

\section{Conclusion}

The synthesized quinoxaline derivatives act as good corrosion inhibitors for the MS in $1.0 \mathrm{M} \mathrm{HCl}$ solution and the inhibiting performance of BMQ is better than FVQ and STQ. Polarization results 
Citation: Lgaz H, Salghi R, Jodeh S, Ramli Y, Larouj M, et al (2016) Understanding the Adsorption of Quinoxaline Derivatives as Corrosion Inhibitors for Mild Steel in Acidic Medium: Experimental, Theoretical and Molecular Dynamic Simulation Studies. J Steel Struct Constr 2: 111. doi:10.4172/2472-0437.1000111
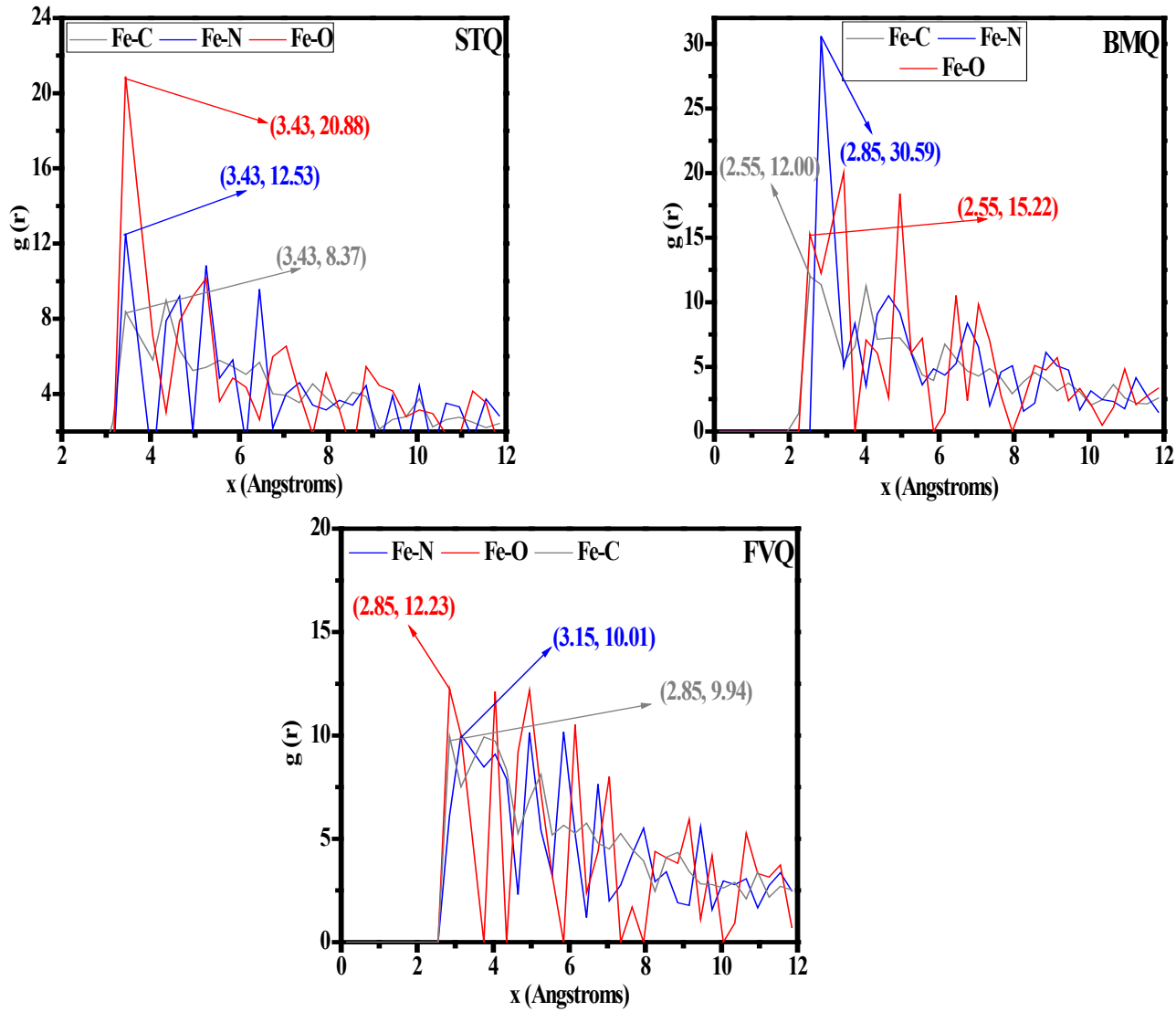

Figure 16: The pair correlation function of $\mathrm{C}, \mathrm{N}$, and $\mathrm{O}$ atoms from three quinoxaline derivatives with $\mathrm{Fe}$ atoms from $\mathrm{Fe}(110)$ surface.

\begin{tabular}{|c|c|c|c|c|c|}
\hline Atom & $P_{k}(N)$ & $P_{k}(N-1)$ & $P_{k}(N+1)$ & $f_{k}^{+}$ & $f_{k}^{-}$ \\
\hline $\mathrm{C} 1$ & 6.21773 & 6.14017 & 6.28938 & 0.07165 & 0.07756 \\
\hline C 2 & 6.27371 & 6.27612 & 6.29525 & 0.02154 & -0.00241 \\
\hline C 3 & 5.84047 & 5.79659 & 5.86754 & 0.02707 & 0.04388 \\
\hline C 4 & 5.88828 & 5.85992 & 5.86958 & -0.0187 & 0.02836 \\
\hline C 5 & 6.20657 & 6.1783 & 6.25852 & 0.05195 & 0.02827 \\
\hline C 6 & 6.2587 & 6.23972 & 6.26991 & 0.01121 & 0.01898 \\
\hline $\mathrm{H} 7$ & 0.75553 & 0.72885 & 0.7859 & 0.03037 & 0.02668 \\
\hline $\mathrm{H} 8$ & 0.75969 & 0.73561 & 0.78621 & 0.02652 & 0.02408 \\
\hline $\mathrm{H} 9$ & 0.74683 & 0.73023 & 0.76739 & 0.02056 & 0.0166 \\
\hline H 10 & 0.75531 & 0.72967 & 0.78345 & 0.02814 & 0.02564 \\
\hline C 11 & 5.84455 & 5.87515 & 5.9476 & 0.10305 & -0.0306 \\
\hline C 12 & 5.36739 & 5.37412 & 5.36786 & 0.00047 & -0.00673 \\
\hline N 13 & 7.43082 & 7.36509 & 7.53289 & 0.10207 & 0.06573 \\
\hline N 14 & 7.59265 & 7.56719 & 7.62214 & 0.02949 & 0.02546 \\
\hline C 15 & 6.2723 & 6.17253 & 6.26119 & -0.01111 & 0.09977 \\
\hline H 16 & 0.74831 & 0.72985 & 0.77186 & 0.02355 & 0.01846 \\
\hline C 17 & 6.15179 & 6.1024 & 6.28275 & 0.13096 & 0.04939 \\
\hline H 18 & 0.7553 & 0.7344 & 0.7717 & 0.0164 & 0.0209 \\
\hline C 19 & 6.108 & 6.0772 & 6.07915 & -0.02885 & 0.0308 \\
\hline C 20 & 6.18418 & 6.14051 & 6.22587 & 0.04169 & 0.04367 \\
\hline C 21 & 6.18885 & 6.16303 & 6.22418 & 0.03533 & 0.02582 \\
\hline C 22 & 6.32592 & 6.30241 & 6.33193 & 0.00601 & 0.02351 \\
\hline H 23 & 0.75973 & 0.73896 & 0.77395 & 0.01422 & 0.02077 \\
\hline C 24 & 6.27262 & 6.25183 & 6.28159 & 0.00897 & 0.02079 \\
\hline
\end{tabular}


Citation: Lgaz H, Salghi R, Jodeh S, Ramli Y, Larouj M, et al (2016) Understanding the Adsorption of Quinoxaline Derivatives as Corrosion Inhibitors for Mild Steel in Acidic Medium: Experimental, Theoretical and Molecular Dynamic Simulation Studies. J Steel Struct Constr 2: 111. doi:10.4172/2472-0437.1000111

Page 15 of 17

\begin{tabular}{|c|c|c|c|c|}
\hline H 25 & 0.75621 & 0.7408 & 0.76651 & 0.0103 \\
\hline C 26 & 5.66646 & 5.60391 & 5.73081 & 0.06435 \\
\hline H 27 & 0.75634 & 0.72941 & 0.778 & 0.02166 \\
\hline H 28 29 & 0.74703 & 0.71908 & 0.7698 & 0.02277 \\
\hline O 30 & 0.7659 & 0.743 & 0.78435 & 0.01845 \\
\hline H 31 & 8.51321 & 8.45657 & 0.02795 & 0.02128 \\
\hline
\end{tabular}

Table 9: Natural population and Fukui functions of STQ calculated at B3LYP/6-31G (d, p) in gas phase.

\begin{tabular}{|c|c|c|c|c|c|}
\hline System & $\begin{array}{c}\text { Total } \\
\text { energy }\end{array}$ & $\begin{array}{c}\text { Adsorption } \\
\text { energy }\end{array}$ & $\begin{array}{c}\text { Rigid } \\
\text { adsorption } \\
\text { energy }\end{array}$ & $\begin{array}{c}\text { Deformation } \\
\text { energy }\end{array}$ & $\begin{array}{l}\mathrm{dEad} / \mathrm{dNi} \\
\text { inhibitor }\end{array}$ \\
\hline $\mathrm{Fe}(110) / \mathrm{BMQ}$ & -196.94 & -204.12 & -169.07 & -35.05 & -204.12 \\
\hline $\mathrm{Fe}(110) / \mathbf{F V Q}$ & -210.27 & -203.73 & -217.17 & 13.45 & -203.73 \\
\hline $\mathrm{Fe}\left(\begin{array}{lll}1 & 1 & 0\end{array}\right) / \mathbf{S T Q}$ & -162.51 & -140.20 & -139.90 & -0.303 & -140.20 \\
\hline
\end{tabular}

10. Ramesh Kumar S, Danaee I, Rashvand Avei M, Vijayan M (2015) Quantum chemical and experimental investigations on equipotent effects of $(+) R$ and $(-)$ $S$ enantiomers of racemic amisulpride as eco-friendly corrosion inhibitors for mild steel in acidic solution. Journal of Molecular Liquids 212: 168-186.

11. Sharma G, Raisinghani P, Abraham I, Pardasani RT, Mukherjee T (2009) Synthesis of quinoxaline quinones and regio-selectivity in their Diels-Alder cycloadditions. Indian Journal of Chemistry (Section B) 48: 1590-1596.

Table 10: Outputs and descriptors calculated by the Monte Carlo simulation for the lowest adsorption. Configurations of studied inhibitors Fe (110) surface (in kcal/ $\mathrm{mol})$.

showed that all tested inhibitors are of mixed type in nature. In the presence of all inhibitors, charge transfer resistance increases and double layer capacitance decreases due to adsorption of the inhibitors' molecules on the MS surface. The experimental results showed that the quinoxaline derivatives adsorb spontaneously on the MS surface and conform to the Langmuir adsorption isotherm. The adsorption process involves physical adsorption. DFT calculations, Monte Carlo simulation and RDF were performed to identify the reactivity of these molecules towards corrosion inhibition, and the results are in good agreement with the experimental investigations. Both experimental and quantum chemical results showed that the order of inhibition efficiency, for the studied compounds is as follows: BMQ $>$ FVQ $>$ STQ.

\section{References}

1. Anejjar A, Salghi R, Zarrouk A (2014) Inhibition of carbon steel corrosion in $1 \mathrm{M} \mathrm{HCl}$ medium by potassium thiocyanate. Journal of the Association of Arab Universities for Basic and Applied Sciences 15: 21-27.

2. Bammou L, Belkhaouda M, Salghi R, Benal O, ZarroukA, et al. (2014) Corrosion inhibition of steel in sulfuric acidic solution by the chenopodium ambrosioides extracts. Journal of the Association of Arab Universities for Basic and Applied Sciences 16: 83-90.

3. Bazzi L, Salghi R, Zine E (2002) Inhibition de la corrosion de l'alliage d'aluminium 6063 au moyen de composés inorganiques dans une solution de chlorure de sodium à $3 \%$. Canadian Journal of Chemistry 80: 106-112.

4. Lgaz H, Benali O, Salghi R, Jodeh S, Larouj M, et al. (2016) Pyridinium derivatives as corrosion inhibitors for mild steel in $1 \mathrm{M} \mathrm{HCl}$ : Electrochemical, surface and quantum chemical studies. Der Pharma Chemica 8: 172-190.

5. Lgaz H, ELaoufir $Y$, Ramli $Y$, Oudda $H$ (2015) Synergistic effect of potassium iodide with (E)-3-(4 methoxystyryl) quinoxalin-2 (1H)-one on the corrosion inhibition of carbon steel in $1.0 \mathrm{M} \mathrm{HCl}$. Der Pharma Chemica 7: 36-45.

6. Anupama KK, Ramya K, Joseph A (2016) Electrochemical and computational aspects of surface interaction and corrosion inhibition of mild steel in hydrochloric acid by Phyllanthus amarus leaf extract (PAE). Journal of Molecular Liquids 216: 146-155.

7. Farag AA, Ismail AS, Migahed M (2015) Inhibition of carbon steel corrosion in acidic solution using some newly polyester derivatives. Journal of Molecular Liquids 211: 915-923.

8. Gupta NK, Verma C, Quraishi MA, Mukherjee AK (2016) Schiff's bases derived from I-lysine and aromatic aldehydes as green corrosion inhibitors for mild steel: Experimental and theoretical studies. Journal of Molecular Liquids 215: 47-57.

9. Murulana LC, Kabanda MM, Ebenso EE (2016) Investigation of the adsorption characteristics of some selected sulphonamide derivatives as corrosion inhibitors at mild steel/hydrochloric acid interface: Experimental, quantum chemical and QSAR studies. Journal of Molecular Liquids 215: 763-779.

12. Thomas KJR, Velusamy M, Lin JT, Chuen CH, Tao YT (2005) Chromophorelabeled quinoxaline derivatives as efficient electroluminescent materials. Chemistry of Materials 17: 1860-1866.

13. Aguirre G, Cerecetto H, Maio DR, González M, Alfaro ME, et al. (2004) Quinoxaline N, N'-dioxide derivatives and related compounds as growth inhibitors of Trypanosoma cruzi. Structure-activity relationships. Bioorganic and Medicinal Chemistry Letters 14: 3835-3839.

14. Olasunkanmi LO, Kabanda MM, Ebenso EE (2016) Quinoxaline derivatives as corrosion inhibitors for mild steel in hydrochloric acid medium: Electrochemical and quantum chemical studies. Physica E: Low-dimensional Systems and Nanostructures 76: 109-126.

15. Obot IB, Obi-Egbedi NO, Odozi NW (2010) Acenaphtho [1, 2-b] quinoxaline as a novel corrosion inhibitor for mild steel in $0.5 \mathrm{MH} 2 \mathrm{SO} 4$. Corrosion Science 52: $923-926$.

16. Saranya J, Sounthari P, Parameswari K, Chitra S (2016) Acenaphtho[1,2-b] quinoxaline and acenaphtho[1,2-b]pyrazine as corrosion inhibitors for mild steel in acid medium. Measurement 77: 175-186.

17. Obot IB, Obi-Egbedi NO (2010) 2, 3-Diphenylbenzoquinoxaline: A new corrosion inhibitor for mild steel in sulphuric acid. Corrosion Science 52: 282-285.

18. Lashkari M, Arshadi MR (2004) DFT studies of pyridine corrosion inhibitors in electrical double layer: solvent, substrate, and electric field effects. Chemical physics 299: 131-137.

19. Verma C, Ebenso EE, Bahadur I, Obot IB, Quraishi MA (2015) 5-(Phenylthio)$3 \mathrm{H}$-pyrrole-4-carbonitriles as effective corrosion inhibitors for mild steel in $1 \mathrm{M}$ $\mathrm{HCl}$ : Experimental and theoretical investigation. Journal of Molecular Liquids 212: 209-218.

20. Al-Mobarak N, Khaled K, Hamed MNH, Abdel-Azimb KM, Abdelshafibet NS (2010) Corrosion inhibition of copper in chloride media by 2-mercapto-4-(pmethoxyphenyl)-6-oxo-1, 6-dihydropyrimidine-5-carbonitrile: Electrochemical and theoretical study. Arabian Journal of Chemistry 3: 233-242.

21. Yan Y, Wang X, Zhang Y, Wang P, Zhang J (2013) Theoretical evaluation of inhibition performance of purine corrosion inhibitors. Molecular Simulation 39 1034-1041.

22. Saha SK, Banerjee $P$ (2015) A theoretical approach to understand the inhibition mechanism of steel corrosion with two aminobenzonitrile inhibitors. RSC Advances 5: 71120-71130.

23. Zhang Z, Tian NC, Huang XD, Shang W, Wu L (2016) Synergistic inhibition of carbon steel corrosion in $0.5 \mathrm{M} \mathrm{HCl}$ solution by indigo carmine and some cationic organic compounds: experimental and theoretical studies. RSC Advances 6: 22250-22268.

24. Xie SW, Liu Z, Han GC, Li W, Liu J, et al. (2015) Molecular dynamics simulation of inhibition mechanism of 3, 5-dibromo salicylaldehyde Schiff's base. Computational and Theoretical Chemistry 1063: 50-62.

25. Lanquist J, Stacey G (1953) 568. Quinoxaline N-oxides. Part II. Oxides of Pysubstituted quinoxalines. Journal of the Chemical Society (Resumed) pp: 28222830 .

26. Ried W, Hinsching S (1956) Synthese heterocyclisch substituierter Äthylene und Butadiene. Justus Liebigs Annalen der Chemie 600: 47-59. 
Citation: Lgaz H, Salghi R, Jodeh S, Ramli Y, Larouj M, et al (2016) Understanding the Adsorption of Quinoxaline Derivatives as Corrosion Inhibitors for Mild Steel in Acidic Medium: Experimental, Theoretical and Molecular Dynamic Simulation Studies. J Steel Struct Constr 2: 111. doi:10.4172/2472-0437.1000111

Page 16 of 17

27. Adardour K, Touir R, Ramli Y, Essassi EM (2013) Comparative inhibition study of mild steel corrosion in hydrochloric acid by new class synthesised quinoxaline derivatives: part I. Research on Chemical Intermediates 39: 1843-1855.

28. Ramli Y, Slimani R, Zouihri H, Lazar S, Essassi EM (2010) 2-Methyl-3-(noctylsulfanyl)quinoxaline. Acta Crystallographica Section E 66: 0992.

29. Lgaz H, Belkhaouda M, Larouj M, Salghi R, Jodeh S, et al. (2016) Corrosion protection of carbon steel in acidic solution by using ylang-ylang oil as green inhibitor. Moroccan Journal of Chemistry 4: 101-111.

30. Larouj M, Belkhaouda M, Lgaz H, Salghi R, Jodeh S, et al. (2016) Experimental and theoretical study of new synthesized organic compounds on corrosion behaviour and the inhibition of carbon steel in hydrochloric acid solution. Der Pharma Chemica 8: 114-133.

31. Becke AD (1992) Density-functional thermochemistry. I. The effect of the exchange-only gradient correction. The Journal of Chemical Physics 96: 21552160.

32. Becke AD (1993) Density-functional thermochemistry. III. The role of exact exchange. The Journal of Chemical Physics 98: 5648-5652.

33. Lee C, Yang W, Parr RG (1988) Development of the Colle-Salvetti correlationenergy formula into a functional of the electron density. Physical Review B 37: 785-789.

34. Frisch M, Trucks G, Schlegel H (2003) Gaussian 03, revision B. 05. Gaussian, Pittsburgh PA.

35. Materials Studio (2013) Revision 6.0. Accelrys Inc., San Diego, USA.

36. Sasikumar Y, Adekunle A, Olasunkanmi L, Bahadur I, Baskar R, et al. (2015) Experimental, quantum chemical and Monte Carlo simulation studies on the corrosion inhibition of some alkyl imidazolium ionic liquids containing tetrafluoroborate anion on mild steel in acidic medium. Journal of Molecular Liquids 211: 105-118.

37. Eivani AR, Zhou J, Duszczyk J (2012) A new approach to incorporating the effect of nano-sized dispersoids on recrystallization inhibition into Monte Carlo simulation. Computational Materials Science 54: 370-377.

38. Solmaz R, Kardaş G, Çulha M, Yazıcı B, Erbil M (2008) Investigation of adsorption and inhibitive effect of 2-mercaptothiazoline on corrosion of mild steel in hydrochloric acid media. Electrochimica Acta 53: 5941-5952.

39. Singh DK, Kumar S, Udayabhanu G, John RP (2016) 4 (N, N-dimethylamino) benzaldehyde nicotinic hydrazone as corrosion inhibitor for mild steel in $1 \mathrm{M} \mathrm{HCl}$ solution: An experimental and theoretical study. Journal of Molecular Liquids 216: 738-746.

40. Singh P, Srivastava V, Quraishi MA (2016) Novel quinoline derivatives as green corrosion inhibitors for mild steel in acidic medium: Electrochemical, SEM AFM, and XPS studies. Journal of Molecular Liquids 216: 164-173.

41. Mourya P, Singh P, Tewari A, Rastogi RB, Singh MM, et al. (2015) Relationship between structure and inhibition behaviour of quinolinium salts for mild stee corrosion: experimental and theoretical approach. Corrosion Science 95: 71-87.

42. Bayol E, Gürten AA, Dursun M, Kayakirilmaz K (2008) Adsorption Behavior and inhibition corrosion effect of sodium carboxymethyl cellulose on mild steel in acidic medium. Acta Physico-Chimica Sinica 24: 2236-2243.

43. Avci G (2008) Inhibitor effect of N,N'-methylenediacrylamide on corrosion behavior of mild steel in $0.5 \mathrm{M} \mathrm{HCl}$. Materials Chemistry and Physics 112: 234-238.

44. Yüce AO, Solmaz R, Kardaş G (2012) Investigation of inhibition effect of rhodanine- $\mathrm{N}$-acetic acid on mild steel corrosion in $\mathrm{HCl}$ solution. Materials Chemistry and Physics 131: 615-620.

45. Yang Z, Zhan F, Pan Y, LYu Z, Han C, et al. (2015) Structure of a novel Benzyl Quinolinium Chloride derivative and its effective corrosion inhibition in 15 wt.\% hydrochloric acid. Corrosion Science 99: 281-294.

46. Hameed RSA (2011) Aminolysis of polyethylene terephthalate waste as corrosion inhibitor for carbon steel in $\mathrm{HCl}$ corrosive medium. Advances in Applied Science Research 2: 483-499.

47. Bentiss F, Lebrini M, Lagrenée M (2005) Thermodynamic characterization of metal dissolution and inhibitor adsorption processes in mild steel/2, 5-bis (n-thienyl)-1, 3, 4-thiadiazoles/hydrochloric acid system. Corrosion Science 47: 2915-2931.

48. Mu G, Li X, Liu G (2005) Synergistic inhibition between tween 60 and $\mathrm{NaCl}$ on the corrosion of cold rolled steel in $0.5 \mathrm{M}$ sulfuric acid. Corrosion Science 47 : 1932-1952.
49. Thomas JM, Thomas WJ, Salzberg H (1967) Introduction to the principles of heterogeneous catalysis. Journal of The Electrochemical Society 114 279C-279C

50. Odewunmi NA, Umoren SA, Gasem ZM (2015) Watermelon waste products as green corrosion inhibitors for mild steel in $\mathrm{HCl}$ solution. Journal of Environmental Chemical Engineering 3: 286-296.

51. Eddy NO, Momoh-Yahaya H, Oguzie EE (2015) Theoretical and experimenta studies on the corrosion inhibition potentials of some purines for aluminum in $0.1 \mathrm{M} \mathrm{HCl}$. Journal of Advanced Research 6: 203-217.

52. Zhang D, Tang Y, Qi S, Donga D, Cang H, et al. (2016) The inhibition performance of long-chain alkyl-substituted benzimidazole derivatives for corrosion of mild steel in HCl. Corrosion Science 102: 517-522.

53. Hussin MH, Rahim AA, Ibrahim MNM, Brosse N (2016) The capability of ultrafiltrated alkaline and organosolv oil palm (Elaeis guineensis) fronds lignin as green corrosion inhibitor for mild steel in $0.5 \mathrm{M} \mathrm{HCl}$ solution. Measurement 78: $90-103$.

54. Zhang Q, Hua YX (2009) Corrosion inhibition of mild steel by alkylimidazolium ionic liquids in hydrochloric acid. Electrochimica Acta 54: 1881-1887.

55. Ramya K, Anupama KK, Shainy KM, Joseph A (2016) Synergistic and hydrogen bonded interaction of alkyl benzimadazoles and urea pair on mild steel in hydrochloric acid: Adsorption, electroanalytical and theoretical studies. Journal of the Taiwan Institute of Chemical Engineers 58: 517-527.

56. Khadiri A, Saddik R, Bekkouche K, Aounitib A, Hammouti B, et al. (2016) Gravimetric, electrochemical and quantum chemical studies of some pyridazine derivatives as corrosion inhibitors for mild steel in $1 \mathrm{M} \mathrm{HCl}$ solution. Journal of the Taiwan Institute of Chemical Engineers 58: 552-564.

57. Odewunmi NA, Umoren SA, Gasem ZM, Ganiyub SA, Muhammad Q (2015) L-Citrulline: An active corrosion inhibitor component of watermelon rind extract for mild steel in $\mathrm{HCl}$ medium. Journal of the Taiwan Institute of Chemical Engineers 51: 177-185.

58. Shahraki M, Dehdab M, Elmi S (2016) Theoretical studies on the corrosion inhibition performance of three amine derivatives on carbon steel: Molecular dynamics simulation and density functional theory approaches. Journal of the Taiwan Institute of Chemical Engineers 62: 313-321.

59. Verma CB, Quraishi M, Singh A (2015) 2-Aminobenzene-1, 3-dicarbonitriles as green corrosion inhibitor for mild steel in $1 \mathrm{M} \mathrm{HCl}$ : Electrochemical, thermodynamic, surface and quantum chemical investigation. Journal of the Taiwan Institute of Chemical Engineers 49: 229-239.

60. Verma C, Quraishi M, Singh A (2016) A thermodynamical, electrochemical, theoretical and surface investigation of diheteroaryl thioethers as effective corrosion inhibitors for mild steel in $1 \mathrm{M} \mathrm{HCl}$. Journal of the Taiwan Institute of Chemical Engineers 58: 127-140.

61. Xu B, Gong W, Zhang K, Chen Y, et al. (2015) Theoretical prediction and experimental study of 1-Butyl-2-(4-methylphenyl)benzimidazole as a novel corrosion inhibitor for mild steel in hydrochloric acid. Journal of the Taiwan Institute of Chemical Engineers 51: 193-200.

62. Xu Z, Yuan S-L, Yan H, Liu C-B (2011) Adsorption of histidine and histidinecontaining peptides on $\mathrm{Au}$ (111): a molecular dynamics study. Colloids and Surfaces A: Physicochemical and Engineering Aspects 380: 135-142.

63. Zhang K, Yang W, Xu B, Liua Y, Yina X, et al. (2015) Corrosion inhibition of mild steel by bromide-substituted imidazoline in hydrochloric acid. Journal of the Taiwan Institute of Chemical Engineers 57: 167-174

64. Hegazy M, Abdallah M, Awad M, Rezk M (2014) Three novel di-quaternary ammonium salts as corrosion inhibitors for API X65 steel pipeline in acidic solution. Part I: experimental results. Corrosion Science 81: 54-64.

65. Quraishi MA (2014) 2-Amino-3, 5-dicarbonitrile-6-thio-pyridines: new and effective corrosion inhibitors for mild steel in $1 \mathrm{M} \mathrm{HCl}$. Industrial \& Engineering Chemistry Research 53: 2851-2859.

66. Jacob KS, Parameswaran G (2010) Corrosion inhibition of mild steel in hydrochloric acid solution by Schiff base furoin thiosemicarbazone. Corrosion Science 52: 224-228.

67. McCafferty E (2010) Introduction to corrosion science. Springer Science \& Business Media.

68. Khalil N (2003) Quantum chemical approach of corrosion inhibition Electrochimica Acta 48: 2635-2640. 
Citation: Lgaz H, Salghi R, Jodeh S, Ramli Y, Larouj M, et al (2016) Understanding the Adsorption of Quinoxaline Derivatives as Corrosion Inhibitors for Mild Steel in Acidic Medium: Experimental, Theoretical and Molecular Dynamic Simulation Studies. J Steel Struct Constr 2: 111. doi:10.4172/2472-0437.1000111

Page 17 of 17

69. Sastri VS, Perumareddi JR (1997) Molecular orbital theoretical studies of some organic corrosion inhibitors. Corrosion 53: 617-622

70. Pearson RG (1988) Absolute electronegativity and hardness: application to inorganic chemistry. Inorganic Chemistry 27: 734-740.

71. Martinez S (2003) Inhibitory mechanism of mimosa tannin using molecular modeling and substitutional adsorption isotherms. Materials Chemistry and Physics 77: 97-102.

72. Lukovits I, Kalman E, Zucchi F (2001) Corrosion inhibitors-correlation between electronic structure and efficiency. Corrosion 57: 3-8.

73. Rodríguez-Valdez LM, Villamisar W, Casales M (2006) Computationa simulations of the molecular structure and corrosion properties of amidoethyl, aminoethyl and hydroxyethyl imidazolines inhibitors. Corrosion Science 48: 4053-4064.

74. Li X, Deng S, Fu H, Li T (2009) Adsorption and inhibition effect of 6 -benzylaminopurine on cold rolled steel in $1.0 \mathrm{M} \mathrm{HCl}$. Electrochimica Acta 54: 4089-4098.

75. Pearson RG (1988) Chemical hardness and bond dissociation energies. Journal of the American Chemical Society 110: 7684-7690.

76. Koch E (2005) Acid-Base interactions in energetic materials: I. the hard and soft acids and bases (HSAB) Principle-Insights to Reactivity and Sensitivity of Energetic Materials. Propellants, Explosives, Pyrotechnics 30: 5-16.

77. Zhou Z, Parr RG (1990) Activation hardness: new index for describing the orientation of electrophilic aromatic substitution. Journal of the American Chemical Society 112: 5720-5724.

78. Gece G (2008) The use of quantum chemical methods in corrosion inhibitor studies. Corrosion Science 50: 2981-2992.

79. Okulik N, Jubert AH (2005) Theoretical analysis of the reactive sites of nonsteroidal anti-inflammatory drugs. Internet Electronic Journal of Molecular Design 4: 17-30.
80. Daoud D, Douadi T, Hamani H (2015) Corrosion inhibition of mild steel by two new S-heterocyclic compounds in $1 \mathrm{M} \mathrm{HCl}$ : Experimental and computational study. Corrosion Science 94: 21-37.

81. Tian H, Li W, Cao K, Hou B (2013) Potent inhibition of copper corrosion in neutral chloride media by novel non-toxic thiadiazole derivatives. Corrosion Science 73: 281-291.

82. Parr RG, Yang W (1984) Density functional approach to the frontier-electron theory of chemical reactivity. Journal of the American Chemical Society 106: 4049-4050.

83. Contreras RR, Fuentealba P, Galván M, Pérez P (1999) A direct evaluation of regional Fukui functions in molecules. Chemical Physics Letters 304: 405-413.

84. Kaya S, Kaya C, Guo L, Kandemirlic F, Tüzün B, et al. (2016) Quantum chemical and molecular dynamics simulation studies on inhibition performances of some thiazole and thiadiazole derivatives against corrosion of iron. Journal of Molecular Liquids 219: 497-504.

85. Verma C, OlasunkanmiL O, Obot IB, Ebenso EE, Quraishi MA (2016) 5-Arylpyrimido-[4,5-b]quinoline-diones as new and sustainable corrosion inhibitors for mild steel in $1 \mathrm{M} \mathrm{HCl}$ : a combined experimental and theoretical approach. RSC Adv 6: 15639-15654.

86. Khaled K, El-Maghraby A (2014) Experimental, Monte Carlo and molecular dynamics simulations to investigate corrosion inhibition of mild steel in hydrochloric acid solutions. Arabian Journal of Chemistry 7: 319-326.

87. Kühnle A (2009) Self-assembly of organic molecules at metal surfaces. Current Opinion in Colloid and Interface Science 14: 157-168.

88. Shi WY, Ding C, Yan JL, Hanb XY, Lva ZM, et al. (2012) Molecular dynamics simulation for interaction of PESA and acrylic copolymers with calcite crystal surfaces. Desalination 291: 8-14. 